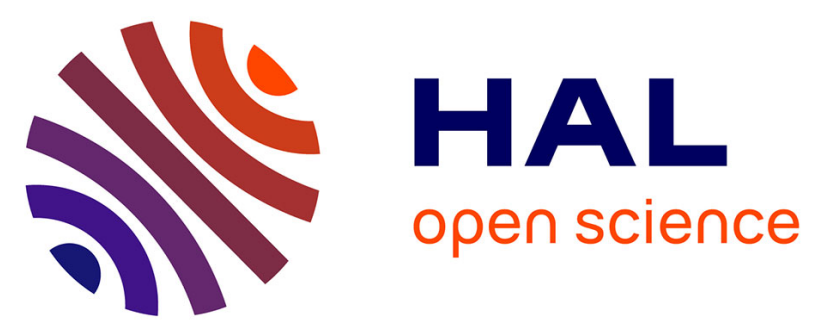

\title{
On the search for representative characteristics of PV systems: Data collection and analysis of PV system azimuth, tilt, capacity, yield and shading
}

Sven Killinger, David Lingfors, Yves-Marie Saint-Drenan, Panagiotis Moraitis, Wilfried van Sark, Jamie Taylor, Nicholas Engerer, Jamie Bright

\section{To cite this version:}

Sven Killinger, David Lingfors, Yves-Marie Saint-Drenan, Panagiotis Moraitis, Wilfried van Sark, et al.. On the search for representative characteristics of PV systems: Data collection and analysis of PV system azimuth, tilt, capacity, yield and shading. Solar Energy, 2018, 173, pp.1087 - 1106. 10.1016/j.solener.2018.08.051 . hal-01882680

\section{HAL Id: hal-01882680 https://hal.science/hal-01882680}

Submitted on 5 Jul 2019

HAL is a multi-disciplinary open access archive for the deposit and dissemination of scientific research documents, whether they are published or not. The documents may come from teaching and research institutions in France or abroad, or from public or private research centers.
L'archive ouverte pluridisciplinaire HAL, est destinée au dépôt et à la diffusion de documents scientifiques de niveau recherche, publiés ou non, émanant des établissements d'enseignement et de recherche français ou étrangers, des laboratoires publics ou privés. 
See discussions, stats, and author profiles for this publication at: https://www.researchgate.net/publication/327279306

\section{On the search for representative characteristics of PV systems Data collection and analysis of PV system azimuth, tilt, capacity, yield and shading}

Article in Solar Energy · August 2018

Dol: 10.1016/j.solener.2018.08.051

\section{CITATIONS}

8

8 authors, including:

Sven Killinger

Fraunhofer Institute for Solar Energy Systems ISE

47 PUBLICATIONS 174 CITATIONS

SEE PROFILE

Yves-Marie Saint-Drenan

MINES ParisTech, PSL Research University

36 PUBLICATIONS 191 CITATIONS

SEE PROFILE
READS

266

A7 David Lingfors

Uppsala University

33 PUBLICATIONS 289 CITATIONS

SEE PROFILE

Panagiotis Moraitis

Utrecht University

14 PUBLICATIONS 44 CITATIONS

SEE PROFILE

Some of the authors of this publication are also working on these related projects:

Project localization and parameterization of existing PV systems using artificial neural networks and image recognition techniques View project

Project Solar charge 2020 View project 


\title{
On the search for representative characteristics of PV systems: Data collection and analysis of PV system azimuth, tilt, capacity, yield and shading
}

\author{
Sven Killinger ${ }^{\mathrm{a}, \mathrm{b}}$, David Lingfors ${ }^{\mathrm{c}}$, Yves-Marie Saint-Drenan ${ }^{\mathrm{d}}$, Panagiotis Moraitis ${ }^{\mathrm{e}}$, Wilfried van Sark $^{\mathrm{e}}$, \\ Jamie Taylor ${ }^{\mathrm{f}}$, Nicholas A. Engerer ${ }^{\mathrm{a}, 2, * *}$, Jamie M. Bright ${ }^{\mathrm{a}, *}$ \\ ${ }^{a}$ Fenner School of Environment and Society, The Australian National University, 2601 Canberra, Australia \\ ${ }^{b}$ Fraunhofer Institute for Solar Energy Systems ISE, 79100 Freiburg, Germany \\ ${ }^{c}$ Department of Engineering Sciences, Uppsala University, Lgerhyddsvgen 1, 75237 Uppsala, Sweden \\ ${ }^{d}$ MINES ParisTech, PSL Research University, O.I.E. Centre Observation, Impacts, Energy, 06904 Sophia Antipolis, France \\ ${ }^{e}$ Copernicus Institute of Sustainable Development, Utrecht University, 3508 TC Utrecht, The Netherlands

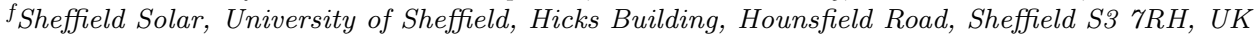

\begin{abstract}
Knowledge of PV system characteristics is needed in different regional PV modelling approaches. It is the aim of this paper to provide that knowledge by a twofold method that focuses on (1) metadata (tilt and azimuth of modules, installed capacity and specific annual yield) as well as (2) the impact of shading.

Metadata from 2,802,797 PV systems located in Europe, USA, Japan and Australia, representing a total capacity of $59 \mathrm{GWp}$ (14.8\% of installed capacity worldwide), is analysed. Visually striking interdependencies of the installed capacity and the geographic location to the other parameters tilt, azimuth and specific annual yield motivated a clustering on a country level and between systems sizes. For an eased future utilisation of the analysed metadata, each parameter in a cluster was approximated by a distribution function. Results show strong characteristics unique to each cluster, however, there are some commonalities across all clusters. Mean tilt values were reported in a range between $16.1^{\circ}$ (Australia) and $35.6^{\circ}$ (Belgium), average specific annual yield values occur between $786 \mathrm{kWh} / \mathrm{kWp}$ (Denmark) and 1,426 kWh/kWp (USA South). The region with smallest median capacity was the UK $(2.94 \mathrm{kWp})$ and the largest was Germany $(8.96 \mathrm{kWp})$. Almost all countries had a mean azimuth angle facing the equator.

PV system shading was considered by deriving viewsheds for $\approx 48,000$ buildings in Uppsala, Sweden (all ranges of solar angles were explored). From these viewsheds, two empirical equations were derived related to irradiance losses on roofs due to shading. The first expresses the loss of beam irradiance as a function of the solar elevation angle. The second determines the view factor as a function of the roof tilt including the impact from shading and can be used to estimate the losses of diffuse and reflected irradiance.
\end{abstract}

Keywords: PV system characteristics, Metadata, Shading, Data analysis 


\footnotetext{
* Corresponding author

** Co-corresponding author

Email addresses: nicholas.engerer@anu.edu.au

(Nicholas A. Engerer), jamie.bright@anu.edu.au (Jamie

M. Bright), jamiebright1@gmail.com (Jamie M. Bright)
}

\section{r}

\section{-}

only accessible for a small number of stakeholders (inverter manufacturers, monitoring solutions providers, etc.). As a result, progress in the area of regional PV power estimation or forecasting can be considered sub-optimal as potential contributors like universities or small companies are partially excluded from access to larger datasets of measurements or metadata. This is still the case despite grid integration of solar energy being considered a strategic societal issue. Therefore, it is the aim of this paper to offer any stakeholders the possibility to develop activities on this research field by collecting, analysing and disseminating metadata on millions of PV systems installed worldwide. To begin, we must establish which metadata are the most important.

Saint-Drenan (2015) carried out a sensitivity analysis and found that the four most influential characteristics impacting PV output generation are: (1) tilt angle and (2) azimuth angle of PV modules, (3) installed capacity and (4) total efficiency (represented herein as the specific annual yield). Furthermore, (5) shading is of crucial influence on the PV power generation but is not accessible from PV system metadata. The impact of shading can only be accessed with considerable effort, e.g. simulations that consider digital elevation models (DEM) including buildings, trees and other obstacles, by analysing PV power profiles or even weekly performance ratios (see Paulescu et al. (2012); Freitas et al. (2015); Lingfors et al. (2018); Tsafarakis et al. (2017) for further reading). Due to its significant influence, a shading analysis complements the focus of this study.

These five identified characteristics are the cen- 
tral focus of this paper because of their general 99 importance for regional PV modelling approaches. 100 The overall aim of this paper is to achieve a full re- 101 producibility of the five characteristics so that they 102 can be used in regional PV power modelling appli- ${ }_{103}$ cations such as nowcasting or forecasting, but also 104 in power simulations that are used for energy sys- 105 tem analysis, studying the grid impact, defining the 106 $\mathrm{PV}$ power potential etc.

\subsection{Related work}

The relevant literature for this research has three ${ }_{111}$ prominent categories: (1) metadata analysis with ${ }_{112}$ intention to improve regional PV power simula- ${ }_{113}$ tions, (2) PV performance due to specific yield, and ${ }_{114}$ (3) models that consider shading analysis.

Category 1: Examples of literature using meta- 116 data to improve regional PV power simulations. ${ }_{117}$ Schubert (2012) provides a useful guidebook for ${ }_{118}$ the simulation of PV power that sketches impor- ${ }_{119}$ tant parts of the simulation chain and delivering 120 assumptions for characteristics. An overview of dif- 121 ferent characteristics of tilt, azimuth, the module ${ }_{122}$ and installation type are given together with sug- 123 gested weights. However, these weights seem to be ${ }_{124}$ assumptions with no datasets being cited as an em- 125 pirical basis and so using these weights in PV sim- 126 ulations raise questions of trust.

Datasets are used by Lorenz et al. (2011), who 128 evaluated the representativeness of a set of ref- 129 erence PV systems to predict regional PV power 130 by analysing the orientation and module types of 131 $\approx 8,000$ systems in Germany. The authors note 132 that their dataset seem to have a disproportionate 133 share of large PV systems and so do not fully represent a larger portfolio.

The problem of poor representativeness was bypassed in Saint-Drenan (2015); Saint-Drenan et al. (2017) by feeding a PV model with metadata statistics from a larger sample of PV systems as opposed to a smaller and unrepresentative subset. They derived joint probabilities of azimuth and tilt from 35,000 systems and clustered them by their system size and geographic location. These empiric distributions where then used to estimate the characteristics of all 1,500,000 PV systems installed in Germany at that time. Saint-Drenan et al. (2018) complemented their earlier research by reproducing it for more European countries using statistical distributions from 35,000 PV systems in Germany and 20,000 in France. This demonstrates the significant potential of generating representative statistical distributions with intended use in regional PV power simulations.

Kühnert (2016, pp. 80-85) followed a similar approach and derived statistical distributions for tilt and azimuth from $\approx 1,300 \mathrm{PV}$ systems in Germany. Based on this portfolio, the author evaluated the representativeness should PV systems be clustered into different geographic regions and system sizes. The authors quantitatively derived recommendations between the two extremes of (1) a portfolio covering all PV systems and (2) a high number of subclasses with a very small number of PV systems. From this, we observe that there must be a well considered clustering approach in order to derive representative subclasses.

Killinger et al. (2017c) detailed a regional PV power upscaling approach which estimated the 
power of $\approx 2,000$ target $\mathrm{PV}$ systems based on 45169 continuously measured PV systems in Freiburg, 170 Germany. Whereas the azimuth and tilt of the 45171 measured systems were known in their case, both 172 parameters were derived through a geographic in- 173 formation system (GIS) based approach for the tar- 174 get $\mathrm{PV}$ systems.

Furthermore, Pfenninger and Staffell (2016) use 176 PV power measurements and incorporate metadata 177 from 1,029 systems in 25 European countries to de- 178 rive empirical correction factors for PV power sim- 179 ulations. A comparison between the analysed tilt 180 and latitude showed an trend towards steeper an- 181 gles at higher latitudes, indicating that metadata 182 might vary with the geographic location.

PV system metadata is thus used to successfully 184 improve regional PV power upscaling across Europe 185 in Pfenninger and Staffell (2016); Killinger et al. 186 (2017c); Saint-Drenan (2015); Saint-Drenan et al. 187 (2017, 2018); Kühnert (2016). These works applied 188 information of azimuth, tilt, installed capacity and 189 the geographic location from PV systems to esti- 190 mate the power output of a larger PV fleet for sim- 191 ilar geographies and different countries. They stand ${ }_{192}$ as an powerful and excellent example for how rep- ${ }_{193}$ resentative metadata distribution statistics can be ${ }^{194}$ employed. It is these examples that guide the first 195 usage of our vast dataset towards deriving repre- 196 sentative metadata distributions.

Category 2: Excerpts of literature that analyse 198 the performance of PV systems. Performance is 199 more complex than just tilt and azimuth as it is 200 inherently influenced by other components, such as 201 soiling and meteorology.

Nordmann et al. (2014) found a positive correla- 203 tion between specific annual yield and incoming irradiance, as well as an observed negative correlation between system performance and ambient temperature. Their data was obtained via web-scraping of Solar-Log $(2,914$ systems in the Netherlands, Germany, Belgium, France and Italy) and collected by participants of the IEA task $(>60,000$ systems in the USA).

Moraitis et al. (2015) observed an increasing yield with decreasing latitude from $\approx 20,000$ systems in Netherlands, Germany, Belgium, France and Italy, also achieved using web-scraping techniques. We therefore expect to observe geographical differences due to latitude and climate.

Taylor (2015) explored the generation of 4,369 distributed systems in the UK to derive the performance ratio and degradation rate. To allow reproducibility, the analysis of the performance ratio was enriched by approximating it with distribution functions. We intend to extend this style of analysis to PV system metadata.

Leloux et al. (2012a) examined data from residential PV systems in Belgium; Leloux et al. (2012b) focused on France. In Belgium, specific annual yield was analysed for 158 systems in 2009 and normalised by a factor which compared the incoming irradiance in this year to a 10 year average. The mean value was $836 \mathrm{kWh} / \mathrm{kWp}$. The same approach led to a mean value of $1,163 \mathrm{kWh} / \mathrm{kWp}$ for 1,635 systems in 2010 in France. Weibull distributions were used throughout both papers to approximate the specific yield and performance indicators; Weibull distributions were selected for visual similarity and not for robustness of fit - we aim to use a more statistically rigorous approach to distribution 
type selection. Furthermore, a relative distribution 238 was provided for combinations of tilt and azimuth. 239 Additionally, the installed capacity was analysed in 240 France, showing a high number of systems with 3241 $\mathrm{kWp}$ or slightly less. The reason for this is due to 242 tax credits being denied for system sizes $>3 \mathrm{kWp} 243$ and a strongly increased VAT for such system sizes 244 (Leloux et al., 2012b). The legal framework can 245 thus have a strong influence on characteristics of 246 PV systems. Further studies exist which analyse 247 the specific energy of PV systems. However, most 248 of these studies are limited to a particular region 249 and less of them propose a parametric approxima- 250 tion of the data studied.

Category 3 - the impact of shading in many ar- 252 ticles is only considered in a highly simplified man- 253 ner, e.g. by setting irradiance values zero above 254 a certain solar zenith angle (Lingfors and Widén, 255 2016), restricting simulations and analyses to time 256 steps with certain solar zenith angles (Elsinga and 257 van Sark, 2015; Elsinga et al., 2017; Jamaly et al., 258 2013; Killinger et al., 2016; Saint-Drenan et al., 259 2017; Yang et al., 2014; Bright et al., 2015), ap- 260 plying constant losses (Mainzer et al., 2017) or as- 261 suming a linear decrease in the PV power values 262 (Schubert, 2012). Several authors expect improve- 263 ments in their results, when the influence of shading 264 is better represented (Bright et al., 2017a,b; Pareek ${ }_{265}$ et al., 2017)

\subsection{Contribution}

Considering the lessons and outcomes of the dif- ${ }_{268}$ ferent studies described in our literature review, we 269 see a clear need for the production of a represen- 270 tative set of distributions to appropriately repre- ${ }^{271}$ sent PV system metadata. Currently, further advancements in regional PV power models in the absence of significant knowledge of metadata is hindered due to several reasons Firstly, implementation is hindered due to lack of access to PV system datasets. Empirically derived distributions of these PV system parameters could replace this need, though currently are only provided for performance indicators (Taylor, 2015) and the specific annual yield (Leloux et al., 2012a). Secondly, with exception of a few studies (e.g., Saint-Drenan et al. (2015)), the issue of sample representativeness is often omitted. This is a major omission, for example, a studied dataset including a majority of roofmounted PV system has to be generalised in order to represent a fleet of systems encompassing a lot of rack-mounted PV systems. Thirdly, most of the identified studies focused on particular PV system characteristics; an integrated analysis encompassing all five key characteristics is required. Furthermore, the influence of shading is in most articles excessively simplified or more commonly excluded. Lastly, studies are mostly limited to a specific country and it is currently difficult to make comparisons between countries to assess applicability. A holistic overview of important parameters of metadata for multiple countries is clearly missing.

The objective of this paper is to address the aforementioned limitations by following the goals below:

1. To collect and process as many data sources as feasible of four identified key metadata parameters (tilt, azimuth, installed capacity and specific annual yield) for PV systems installed worldwide (section 2), 
2. To explore the characteristics of these key pa- 305 rameters and their associated interdependen- 306 cies (section 3.1),

3. To propose a a clustering approach to allow 308 representative generalisation of our datasets 309 (section 3.2),

4. To provide an eased access to the character- ${ }^{311}$ istics of each key parameter by fitting distri- 312 bution functions to the observed probabilities 313 (section 4),

5. To propose a method that evaluates the im- ${ }^{315}$ pact of shading (section 5.1) and which derives ${ }^{316}$ generalised findings for improved consideration ${ }^{317}$ and implementation (section 5.2).

The influence of meteorological conditions, panel degradation and soiling are not considered within this research, beyond those losses that are inherently and statically contained within the specific annual yield. Whilst they are highly interesting topics and research avenues that could be explored, we are more keenly interested in comparisons and parametrisations of PV system metadata and reserve such topics for future research, more ideas of which are presented in section 6 . A summary of the paper is then given in section 7. In the Appendix A, the forms of the distributions used in this paper are defined and their fitted variables provided.

\section{Collection and processing of PV system metadata}

An intensive effort has been conducted to iden- 336 tify, collect and prepare good sources of PV sys- 337 tem metadata. Some of the major monitoring 338 companies and inverter manufacturers have been 339 contacted. In parallel, free information on several solar portals have also been used to gather our dataset either by downloading or web-scraping techniques. Ultimately, we obtained a dataset containing 2,802,797 PV systems located in Europe, USA, Japan and Australia, which represents a total capacity of 59 GWp (14.8\% of installed capacity worldwide). Every system in our records reported an installed capacity. However, the other parameters were not always reported. The systems in our database that reported a valid tilt/azimuth only have a relative share from the worldwide installed capacity of $1.7 \%$. Geographic position was almost as often reported as installed capacity and the relative share is $14.5 \%$. The specific annual yield has a relative share of $11 \%$. Further detail of the parameter shares and subsequent quality filtering are found in Table A.5.

An overview of the regions covered by our study, the characteristics of the datasets and their sources are provided in Table 1. For some countries, data is derived from multiple sources. It shouldn't be ruled out that systems could be listed multiple times, leading to duplicates in the analysis. Due to the nature of reporting, a single PV system may not have the same metadata in different datasets and so it is accepted that this is an inherent error. The inhomogeneous nature of the datasets motivated us to apply some preprocessing operations to ensure that only valid system measurements are considered in our analysis and all datasets are in a consistent format. Some of these operations act as quality filters. They were developed based on our empiric experiences with the datasets and are shortly justified where presented. 
Table 1: Regions, parameters and data sources. "Rest of Europe" contains different European countries not already listed with less than 1,000 systems each. The cumulated capacity is given in MWp and, where available, as a relative share of the total installed capacity in a region (own calculations based on IEA (2018) with data from 2016 and National Grid UK (2018) in case of UK with data from 2018).

\begin{tabular}{|c|c|c|c|c|c|c|}
\hline $\begin{array}{l}\text { Region } \\
-\end{array}$ & $\begin{array}{r}\text { No. } \\
\text { systems } \\
-\end{array}$ & $\begin{array}{c}\text { Tilt \& azi. } \\
\qquad\left({ }^{\circ}\right)\end{array}$ & $\begin{array}{l}\text { Capacity } \\
(\mathrm{kW} / \mathrm{kWp})\end{array}$ & $\begin{array}{l}\text { Spec. ann. yield } \\
\text { (kWh/kWp) }\end{array}$ & $\begin{array}{l}\text { Cumulated Capacity } \\
\text { (MWp) / \% of total }\end{array}$ & $\begin{array}{l}\text { Source } \\
-\end{array}$ \\
\hline Australia & 4,055 & $\checkmark$ & $\checkmark$ & $x$ & $30 / 0.42$ & pvoutput.org \\
\hline \multirow{4}{*}{ Austria } & 385 & $\checkmark$ & $\checkmark$ & 2012-2016 & $4 / 0.33$ & solar-log.com \\
\hline & 280 & $\checkmark$ & $\checkmark$ & $x$ & $2 / 0.14$ & suntrol-portal.com \\
\hline & 268 & $\checkmark$ & $\checkmark$ & $2015-2017$ & $2 / 0.17$ & sonnenertrag.eu \\
\hline & 112 & $\checkmark$ & $\checkmark$ & $2015-2017$ & $1 / 0.04$ & pvoutput.org \\
\hline \multirow[t]{3}{*}{ Belgium } & 4,535 & $\checkmark$ & $\checkmark$ & $2012-2016$ & $149 / 3.93$ & solar-log.com \\
\hline & 3,365 & $\checkmark$ & $\checkmark$ & 2015-2017 & $17 / 0.45$ & bdpv.fr \\
\hline & 541 & $\checkmark$ & $\checkmark$ & $2015-2017$ & $12 / 0.32$ & sonnenertrag.eu \\
\hline \multirow[t]{3}{*}{ Denmark } & 933 & $\checkmark$ & $\checkmark$ & $2012-2016$ & $7 / 0.80$ & solar-log.com \\
\hline & 630 & $\checkmark$ & $\checkmark$ & $x$ & $4 / 0.42$ & suntrol-portal.com \\
\hline & 542 & $\checkmark$ & $\checkmark$ & 2015-2017 & $2 / 0.27$ & pvoutput.org \\
\hline \multirow[t]{2}{*}{ France } & 20,935 & $\checkmark$ & $\checkmark$ & $2015-2017$ & $93 / 1.17$ & bdpv.fr \\
\hline & 558 & $\checkmark$ & $\checkmark$ & 2012-2016 & $8 / 0.10$ & solar-log.com \\
\hline \multirow[t]{4}{*}{ Germany } & $1,664,967$ & $x$ & $\checkmark$ & $2012-2016$ & $41,478 / 98.76$ & bundesnetzagentur.de \\
\hline & 23,536 & $\checkmark$ & $\checkmark$ & 2012-2016 & $547 / 1.30$ & solar-log.com \\
\hline & 6,561 & $\checkmark$ & $\checkmark$ & $\times$ & $124 / 0.29$ & suntrol-portal.com \\
\hline & 6,447 & $\checkmark$ & $\checkmark$ & $2015-2017$ & $112 / 0.27$ & sonnenertrag.eu \\
\hline \multirow[t]{3}{*}{ Italy } & 2,506 & $\checkmark$ & $\checkmark$ & $2012-2016$ & $30 / 0.15$ & solar-log.com \\
\hline & 1,068 & $\checkmark$ & $\checkmark$ & 2015-2017 & $9 / 0.04$ & pvoutput.org \\
\hline & 358 & $\checkmark$ & $\checkmark$ & 2015-2017 & $11 / 0.06$ & sonnenertrag.eu \\
\hline Japan & 5,233 & $\checkmark$ & $\checkmark$ & $2012-2017$ & $42 / 0.09$ & jyuri.co.jp \\
\hline \multirow[t]{4}{*}{ Netherlands } & 7,180 & $\checkmark$ & $\checkmark$ & $2015-2017$ & $31 / 1.08$ & pvoutput.org \\
\hline & 1,115 & $\checkmark$ & $\checkmark$ & 2012-2016 & $14 / 0.49$ & solar-log.com \\
\hline & 917 & $\checkmark$ & $\checkmark$ & $2015-2017$ & $9 / 0.31$ & sonnenertrag.eu \\
\hline & 290 & $\checkmark$ & $\checkmark$ & x & $2 / 0.07$ & suntrol-portal.com \\
\hline \multirow{3}{*}{$\begin{array}{l}\text { Rest of } \\
\text { Europe }\end{array}$} & 1,191 & $\checkmark$ & $\checkmark$ & $2012-2016$ & $23 /-$ & solar-log.com \\
\hline & 566 & $\checkmark$ & $\checkmark$ & 2015-2017 & $5 /-$ & pvoutput.org \\
\hline & 133 & $\checkmark$ & $\checkmark$ & $2015-2017$ & $2 /-$ & sonnenertrag.eu \\
\hline \multirow[t]{2}{*}{ UK } & 18,543 & $\checkmark$ & $\checkmark$ & $2015-2016$ & $58 / 0.45$ & microgen- \\
\hline & 2,286 & $\checkmark$ & $\checkmark$ & $2015-2017$ & $9.5 / 0.07$ & $\begin{array}{l}\text { database.sheffield.ac.uk } \\
\text { pvoutput.org }\end{array}$ \\
\hline \multirow[t]{2}{*}{ USA } & $1,020,585$ & $\checkmark$ & $\checkmark$ & 2017 & $16,521 / 32.39$ & openpv.nrel.gov \\
\hline & 2,176 & $\checkmark$ & $\checkmark$ & 2015-2017 & $17 / 0.03$ & pvoutput.org \\
\hline
\end{tabular}


Longitude and latitude: In cases where this 375 information was not provided, the geographical co- 376 ordinates were derived from OpenStreetMap using 377 other given information such as the zip-code, city 378 name, state name, etc. Erroneous locations outside 379 the specific region are set NA. For confidentiality 380 reasons geographic information was provided sep- 381 arately from the other parameters in case of the ${ }_{382}$ 18,543 systems from Sheffield Solar. The derived 383 longitude and latitude are not required to be highly 384 accurate to suit the needs of this paper as they are 385 purely used for trend analysis when studying rough 386 relationships to other parameters and for visualiza- 387 tion purposes. The ability to allocate a PV system 388 to a specific country is certain in all cases.

Tilt and azimuth: Unfortunately, this impor- 390 tant metadata is not available from all sources. In 391 case of Australia the provided data was imprecise ${ }_{392}$ ( $45^{\circ}$ steps in the azimuth) and thus estimated by 393 the approach described in Killinger et al. (2017b) 394 and improved in Killinger et al. (2017a) as the PV ${ }_{395}$ power data was available. As Australia is on the ${ }_{396}$ southern hemisphere, azimuth angles were trans- 397 formed to normalise the angles expressed for both 398 hemispheres. Within this paper, we consider $-90^{\circ} 399$ to be east, $90^{\circ}$ to be west, with $0^{\circ}$ representing 400 south in the Northern hemisphere and north in the 401 Southern hemisphere. Multi-array systems are not 402 considered in this paper. In a few of the listed ${ }_{403}$ datasets, an excessive amount of tilt values with 404 $0^{\circ}$ or $1^{\circ}$ and azimuth values of $-180^{\circ}$ are reported. 405 E.g. the Australian dataset reported $36 \%$ of all sys- 406 tems having a tilt angle $\leq 1^{\circ}$. Visual inspections 407 based on aerial images and results from the afore- 408 mentioned parametrisation, however, showed that 409 such small tilt angles were very rare and regularly incorrectly reported. From previous work with various datasets, we know that such boundary values are sometimes used as a default when data is missing. As we have no quality control measures on the data, the validity of the data at these boundary values is in question and so are removed from consideration. Tilt $\leq 1^{\circ}$ or $>89^{\circ}$ and azimuth $<-179^{\circ}$ or $>179^{\circ}$ are thus set NA.

Specific annual yield: There are many instances of systems reporting a specific annual yield of $0 \mathrm{kWh} / \mathrm{kWp}$. Without further information from the datasets, it is not possible to distinguish whether this is a default value for missing data or a valid measurement. We expect that both cases regularly occur and so we must remove any input of $0 \mathrm{kWh} / \mathrm{kWp}$ from our analysis. Furthermore, the specific yield of a system is set NA if it was installed within the year of consideration to ensure that a full year of generation is the basis for the annual yield. In order to compensate annual meteorological fluctuations within a dataset of a country, all values within a year are divided by the ratio between the mean value from all systems in this year and the average of the mean values from all reported years. A similar approach is applied in Leloux et al. (2012a). In datasets reporting a continuous time series, the specific annual yield was derived by the summation of the normalised PV power values. Only systems which have less than 10 days / $\approx 2.7 \%$ of missing time steps in their generation data are considered. The vast minority of systems in the datasets reported specific annual yield values that significantly exceed any meteorological potential. We believe that such values are either erroneous reports 
of either yield or the installed capacity, as the lat- 445 ter is used in some datasets to derive the former ${ }_{446}$ through division. Whereas Taylor (2015) applied ${ }_{447}$ a statistical based upper limit for outliers, a fixed ${ }_{448}$ limit of $2,000 \mathrm{kWh} / \mathrm{kWp}$ was used in this paper. ${ }_{449}$ The fixed value was chosen to ensure a reliable fil- 450 tering even though the quality and range of values 451 may differ for the various datasets. A threshold value of $2,000 \mathrm{kWh} / \mathrm{kWp}$ acknowledges the increas- ${ }_{452}$ ing risk of erroneous data beyond this value and is a very cautious limit with the aim of avoiding any erroneous filtering. In fact, this limit was only ex- 454 ceeded in $2.65 \%$ of all systems that reported a yield 455 value from openpv.nrel.gov where we observed the 456 largest values within the study and only for $0.084 \% 457$ of all systems in this study.

Please note that, regarding the installed capac- 459 ity, no pattern was recognised that led us to be- 460 lieve that there were any systematic quality issues. 461 The same applies for the other parameters that were 462 only available for some datasets, such as informa- 463 tion about the network connection for Germany as 464 visualised in Figure 2. Hence, the data was taken 465 on an as-is basis in these cases.

A summary of the impact of our proposed qual- ${ }_{467}$ ity control criteria is provided in the appendix in 468 Table A.5 where percentages of removed data are ${ }_{469}$ presented. Data from pvoutput.org were strongly 470 affected by the filtering of the low tilt values and 471 justify the need of such a quality control. There 472 is a significantly higher share of systems filtered 473 by $<-179^{\circ}$ when compared to the filter for az- 474 imuths $>179^{\circ}$. This is because south is defined 475 as $180^{\circ}$ in some datasets and are therefore trans- 476 formed by subtracting $180^{\circ}$. Invalid entries in the ${ }_{477}$ same datasets were defined as $0^{\circ}$ and subsequently filtered post-transformation by the lower threshold value for azimuth values. Insufficient information was given to derive the exact location for PV systems, mostly from pvoutput.org. All valid parameter entries that have passed the quality control are used for the analysis in the next two sections.

\section{Analysis of PV system metadata}

\subsection{Analysis of parameters and dependencies}

The datasets presented in section 2 are very inhomogeneous with large differences in the number of systems in each region and the availability of parameters. Before starting to explore individual clusters, typical ranges of these parameters and potential dependencies between them shall be studied on a global dataset. The general principle of the global dataset is that every region has the same weight. Consider Table 1, should all data be used to make global statistics, the results would be biased towards the countries with more data (USA and Germany). Therefore, a normalisation method must be employed to weight countries equally. Its derivation follows the following procedure:

(1) Specific annual yield is the only parameter that exists multiple times for each PV system. To evenly weight all systems, only one normalised specific yield value per system is considered by randomly selecting a year. This procedure was preferred to others such as e.g. taking the mean value for all values of a system in order to conserve system specific variability between years. (2) For each combination of two parameters (e.g. tilt and specific annual yield) the algorithm counts the number 

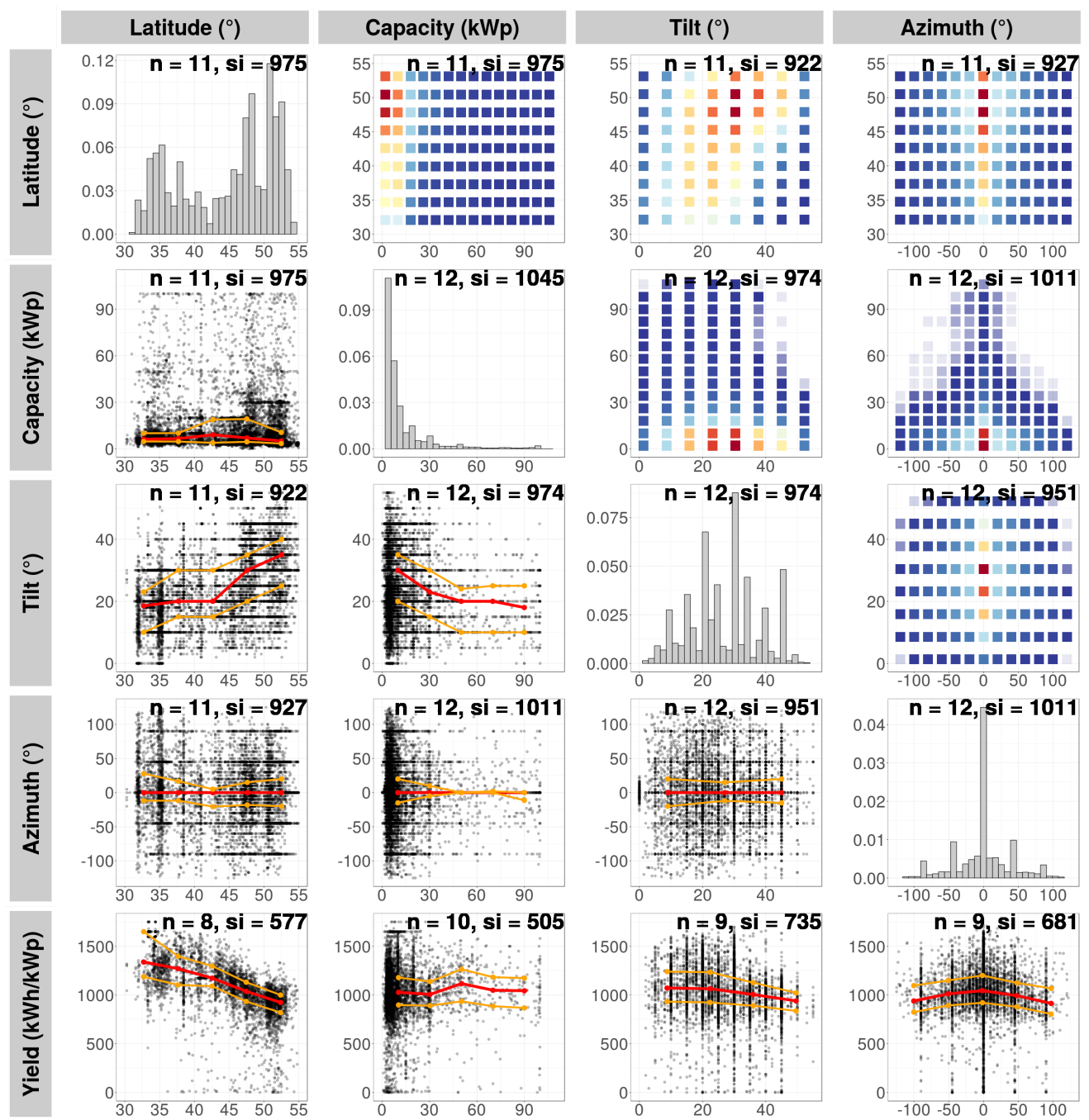

Yield (kWh/kWp)

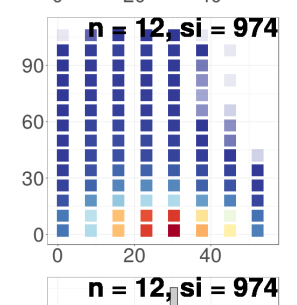

30.

$-100-50$ o 50 100

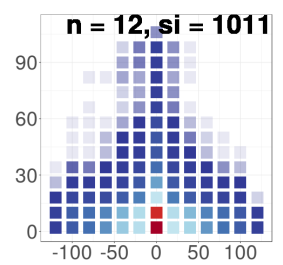

$55 n=\mathbf{8}, \mathbf{s i}=\mathbf{5 7 7}$

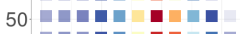

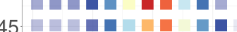

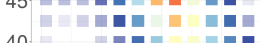

40 붐ำ

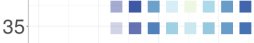

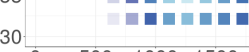

$n=10, \mathbf{s i}=505$

90

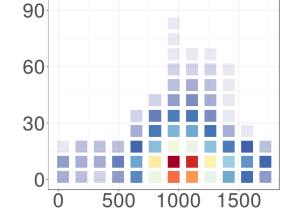

n=12, si $=951$
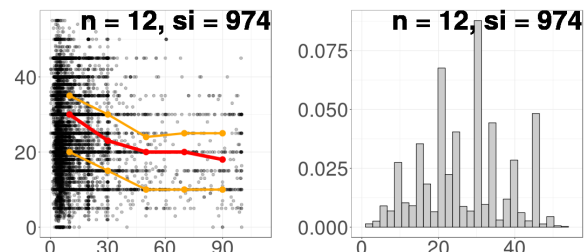

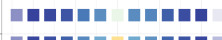

40 ำ

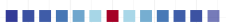

0ก

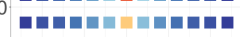

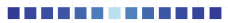

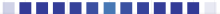

$-100-50 \quad 0 \quad 50 \quad 100$
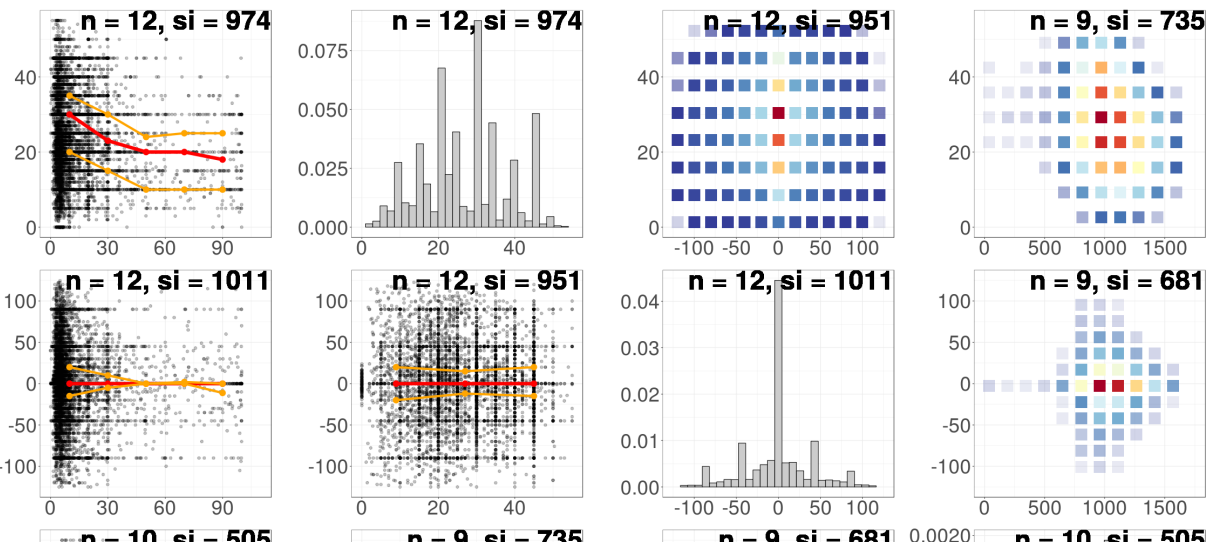

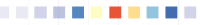

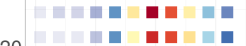

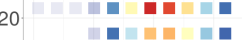

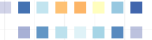

무뭄

$0 \quad 500 \quad 1000 \quad 1500$
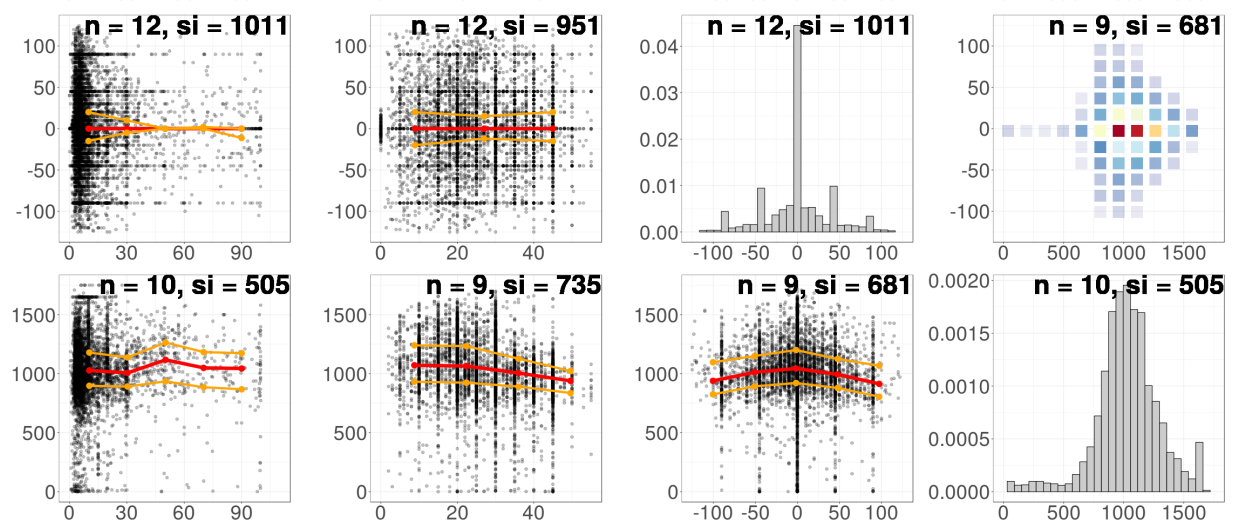

Figure 1: Hybrid graphic with plots of the different parameter pairs from the global dataset. The plots below the diagonal are scatter plots with the $25 \%, 50 \%$ and $75 \%$ quantiles as coloured lines. Plots on the diagonal are 1D-histograms of that parameter. Plots above the diagonal are 2D-histograms of the parameter pairs; the change in colour from white to red is an indication of probability and its distribution. The 2D-histograms and scatter plots have the parameter of their column on the $\mathrm{x}$-axis and the parameter of their row on the y-axis. Note that each scatter and 2D-histogram pair have opposite axes but are identical data. 1D-histograms are the only exception with having displayed the density on the y-axis. For reasons of simplification the absolute value of the latitude is taken in these plots to make results from the northern and southern hemisphere comparable. The bold number in each plot shows the number of countries (n) which are considered in the plot as well as the sampling size (si).

of couples per region that have valid reports in both ${ }_{482}$ parameters that have passed the quality control in ${ }^{483}$ section 2. Only regions with a sample size of at ${ }^{484}$ least 500 complete couples are considered to ensure ${ }_{485}$ statistical relevance. (3) The smallest number of complete couples from all regions is taken to define the sample size for the global dataset. This way, the same number of complete couples is taken 
from each region. Therefore, all of the data is con- 521 sidered for the region with the smallest number of 522 complete couples. In all other regions, the same ${ }_{523}$ number of couples is randomly selected. To avoid 524 under-representation of larger systems, the selec- 525 tion probability is linearly weighted with installed 526 capacity, not frequency.

The significant advantage of this procedure is 528 that regional characteristics are evenly weighted 529 and the availability for each pair of parameters is 530 individually considered. The disadvantage is that 531 many systems are randomly banned due to the re- 532 gion with least availability. We applied different 533 methods of sub-sampling the data, however, the re- 534 sulting global data was quite insensitive to differ- 535 ent sampling procedures indicating the robustness 536 of our approach.

Results from the global dataset are displayed 538 in Figure 1 and the following observations can be 539 made:

Latitude: To have a robust quantity of data, ${ }_{541}$ $\mathrm{PV}$ systems in latitudes between $30^{\circ}$ and $55^{\circ}$ are 542 studied. Latitude does not show any obvious in- 543 fluence to the installed capacity or azimuth angle. 544 The tilt angle shows a tendency to increase with 545 an increasing latitude, corroborating the same ob- 546 servation by Pfenninger and Staffell (2016) between 547 the latitude ranges in the study. This finding agrees 548 with studies showing that systems should have a 549 smaller tilt closer to the equator in order to opti- 550 mise their annual yield (Š́ri et al., 2007). It is still 551 surprising since many systems in our analysis are 552 installed on roofs and strongly depend on the roofs' inclination. It can be suggested that the roof pitch 554 has a tendency to be steeper at higher latitudes in 555 our datasets and agrees with similar observations in Europe (McNeil, 1990, p. 883). Furthermore, a linear decline in the specific annual yield is observed with an increasing latitude. This occurs in accordance to the tendency of a higher solar potential in regions closer to the equator (Súri et al., 2007).

Installed capacity: Within the plot, only systems $<100 \mathrm{kWp}$ are displayed for ease of visualisation. Even though the sampling weights in preference of larger systems, there is a clear concentration of smaller system sizes. There is a visual trend towards smaller tilts with an increasing installed capacity. Furthermore, there is a clear observation that larger capacity systems are consistently oriented towards the equator whereas smaller systems have a much broader range of orientation. A dependency between the installed capacity and the specific annual yield cannot be observed in the global dataset. Despite that, we would expect that the efficiency of larger systems is usually higher and systems better maintained. Most likely, this trend is invisible here since data from many geographic regions were sampled. This hypothesis is checked in section 4 . The finding that PV system size has interdependencies on the other parameters can be reaffirmed with everyday observations; smaller systems are in most cases mounted on the roof of residential buildings, medium systems are typically found on farming houses or industrial buildings, and large systems are mounted on a rack on the ground.

Tilt: Tilt in the dataset mainly occurs in a range up to $50^{\circ}$ and is often reported in steps of $5^{\circ}$, though reporting steps of $10^{\circ}$ are also common. No discernible trend between tilt and azimuth is ob- 

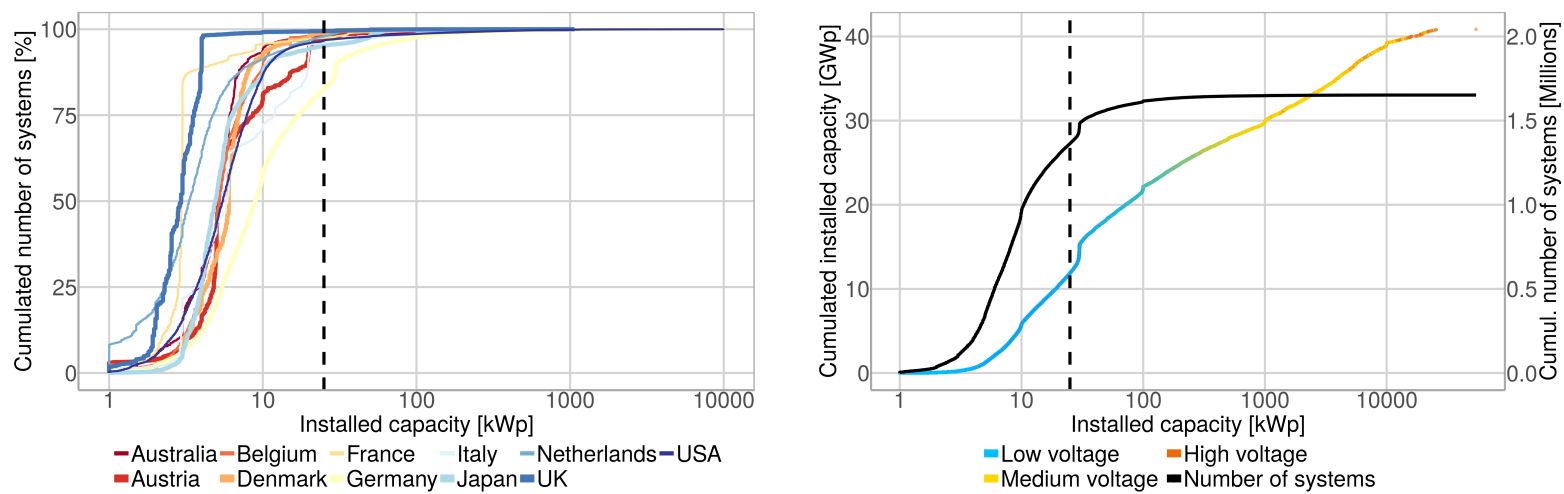

Figure 2: The installed capacity and its relationship to the relative share of systems for different countries (left). The line width and colours vary to simplify the differentiation. The cumulative installed capacity in case of Germany is shown in the right plot represented by the coloured line (colouration indicating the network connection) whereas the black line represents the cumulative number of systems. The dashed line indicates $25 \mathrm{kWp}$, which is used to sub-categorise the data in section 3.2 .

served, however the 2D-histogram shows a signifi- 577 est $15^{\circ}$.

cant density peak around the most frequent combination of azimuth and tilt with a radially decreasing 578 probability, this was also observed by Saint-Drenan 579 (2015); Killinger et al. (2017c). A decrease in the 580 specific annual yield can be seen with an increas- 581 ing tilt. This might be caused by the finding that 582 tilt is usually smaller for decreasing latitudes which 583 occur in combination with an increased specific an- 584 nual yield.

Azimuth: There is a significant peak of azimuth ${ }_{587}$ angles pointing south (north in Australia). It is 588 probable that this distinct peak is due to the tar- 589 geted approach of solar installers who favour equa- 590 torial orientated rooftops due to performance ben- 591 efits. Indeed, azimuth angles tend towards reach- 592 ing a higher specific annual yield with systems ori- 593 ented towards $0^{\circ}$. In general, outliers reach a range ${ }_{594}$ of $+/-100^{\circ}$ with discrete reporting intervals being 595 visible in the 1D-histogram and scatter plot, e.g. 596 databases only requiring azimuth reported to near- 597
Specific annual yield: The 1D-histogram of yield shows the most distinct shape of all parameters with a peak around $1,000 \mathrm{kWh} / \mathrm{kWp}$. Furthermore, there is a small peak at $1,650 \mathrm{kWh} / \mathrm{kWp}$ which is caused by PV systems in southern regions of the USA. It is not possible with the limited latitude study area to infer that the regression of specific yield with latitude will extend towards the equator; climatic regions are expected to be far more influential on the specific yield whereby around the equator there is a significant presence of clouds, and around the tropics there tends to be desert. It is probable that the secondary peak above $1,650 \mathrm{kWh} / \mathrm{kWp}$ is for systems installed in particularly arid regions found in southern USA, however, climatic influence is outside the scope of this paper and is reserved for future study. The specific annual yield has the most visually recognisable trends to all other parameters, demonstrating the strong inter-relationship. There is a need for a more de- 
tailed multi-variable analysis between specific an- 632 nual yield and the other parameters. However, due ${ }_{63}$ to its extra complexity it falls outside the scope of 634 this paper.

\subsection{Representativeness of clusters}

In the previous section, important characteris- 638 tics of PV systems and their dependencies were de- 639 rived. With exception of the annual specific yield 640 and installed capacity in Germany, metadata of all ${ }_{641}$ the installed systems within the different regions 642 is not known (e.g. we have access to 4,055 systems 643 from Australia when there are an estimated 1.8 mil- 644 lion installed). This restriction questions the rep- 645 resentativeness and re-usability of our observations 646 when using the statistics of a subset of systems to ${ }_{647}$ infer the statistics of the remainder because some ${ }_{648}$ characteristics could be over- or underrated in our 649 datasets. To achieve representation, a solution is to 650 sub-categorise metadata from the PV systems into 651 smaller and more homogeneous clusters. By doing 652 so, an end-user can use the statistics of the clusters 653 and weight them individually by the probability of 654 occurrence. Prior to an approximation of metadata 655 in section 4 , it is the objective within this section to 656 define groupings or clusters of PV system that allow 657 the derivation of representative characteristics. $\quad 658$

The interdependency analysis reveals two domi- 659 nating parameters which show multiple dependen- 660 cies to others: (1) The installed capacity and (2) ${ }_{661}$ a geographical influence (c.f. absolute latitudes 662 are used to account for hemispheres). These two 663 findings are in accordance with Kühnert (2016); 664 Saint-Drenan (2015); Saint-Drenan et al. (2017) 665 who analysed azimuth and tilt for different classes 666 of installed capacity and multiple regions. Such a separation has the benefit to acknowledge the impact from these two dominating parameters on others, while still allowing us to derive meaningful statistics within a chosen cluster. As Kühnert (2016) evaluates, a balance must be found between the number and size of the clusters, in order to guarantee that each class includes a sufficient number of data to be representative.

The left plot in Figure 2 provides further insights into the system size and its relative share for different countries in this paper. Differences can be observed between countries but all show a heightened concentration towards small scale systems with a relative share between 60\% (Germany) and 99\% (UK) of systems $<10 \mathrm{kWp}$. Whereas most datasets only cover a selection of systems within a country, the dataset in case of Germany (bundesnetzagentur.de) covers the vast majority of systems and is detailed on the right plot. Almost one million out of the 1.6 millions German systems are smaller than $10 \mathrm{kWp}$ but in total, with an aggregated capacity of $\approx 5 \mathrm{GWp}$, they only represent $\approx 12 \%$ of the installed capacity. Another 650,000 systems occur in a range between 10 and $100 \mathrm{kWp}$ and cover additional $\approx 17.5$ GWp. Only 35,000 systems are $>$ $100 \mathrm{kWp}$ yet are responsible for half of the total installed capacity.

On the search of a threshold value to split the datasets into representative clusters, a system size of $25 \mathrm{kWp}$ was chosen by considering: (1) An installed capacity of $25 \mathrm{kWp}$ is an adequate size between typical roof mounted systems and larger plants, particularly as larger capacities are linked to larger physical space requirements. (2) So even 

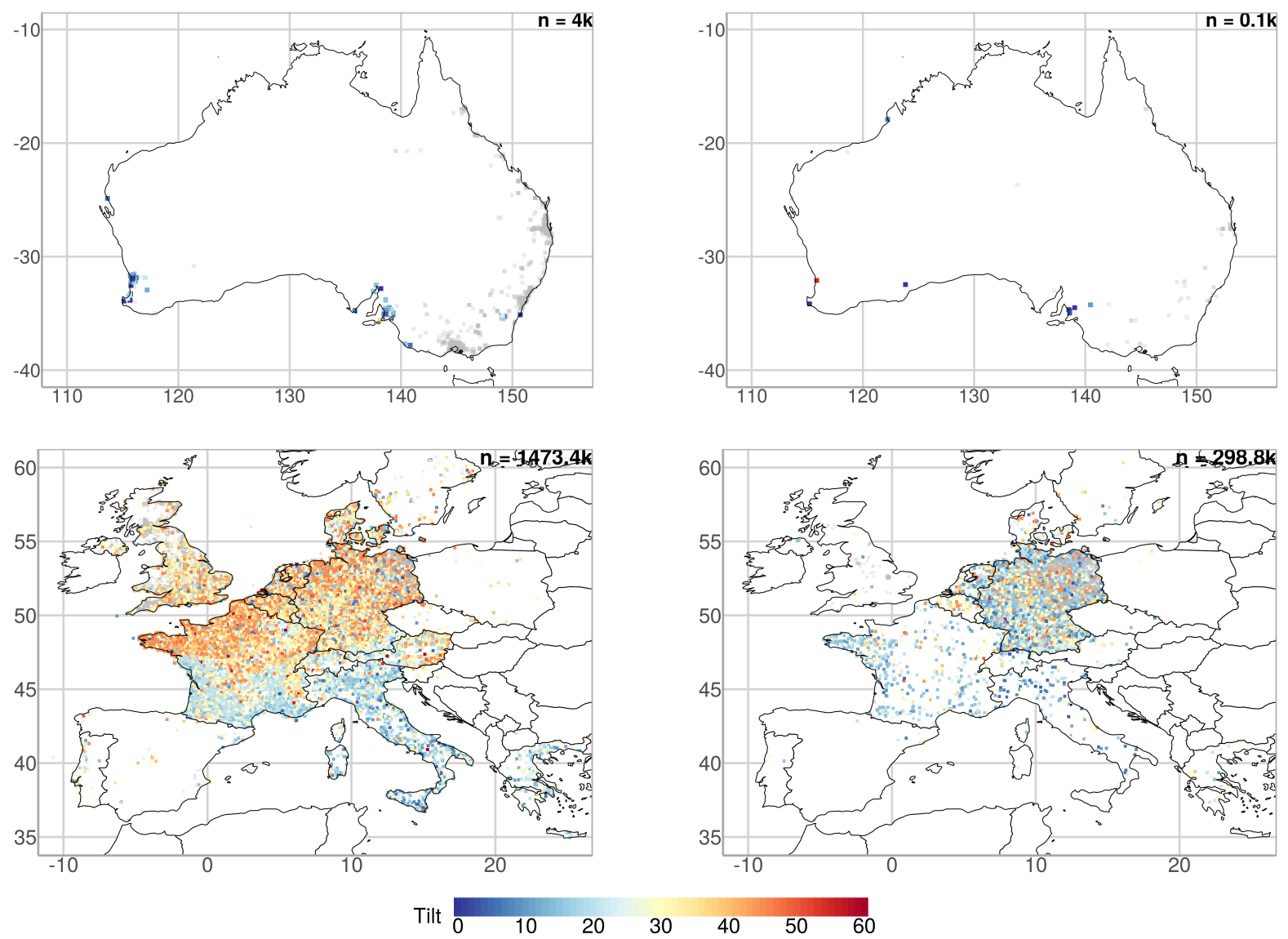

Figure 3: Maps for Australia (top) and Europe (bottom). The left column shows systems $\leq 25 \mathrm{kWp}$ and the right column systems $>25 \mathrm{kWp}$. Systems which do not report tilt are in grey colour.

though the number of larger systems is rather low in 680 most countries, their strong contribution to the total power generation and the knowledge that characteristics change with the system size justify a consideration in a separate cluster. The threshold value of $25 \mathrm{kWp}$ is displayed as a dashed vertical line in Figure 2. If the threshold value were higher, only a small number of systems would be left in the upper cluster and the derivation of representative statistics impeded. (3) Several threshold values were trialled in our analysis. A value of $25 \mathrm{kWp}$ was finally decided upon as it satisfied the aforementioned criteria and passed visual inspection by producing dis- tinct distribution curves.

Both the impact of system size and the geographical influence can be studied in respect to the tilt angle of systems in Figure 3 and Figure 4. All regions show a tendency towards smaller tilt angles for system sizes $>25 \mathrm{kWp}$. Especially for systems $\leq 25 \mathrm{kWp}$ in Europe, the dependency between latitude and tilt can be observed by an increasing tilt angle from Italy to Denmark. However, it should be noted that the spatial influence is not only limited to a pure geographical relationship; the spatial impact depends on regulations and incentives which often occur on a national level. The policy situation 

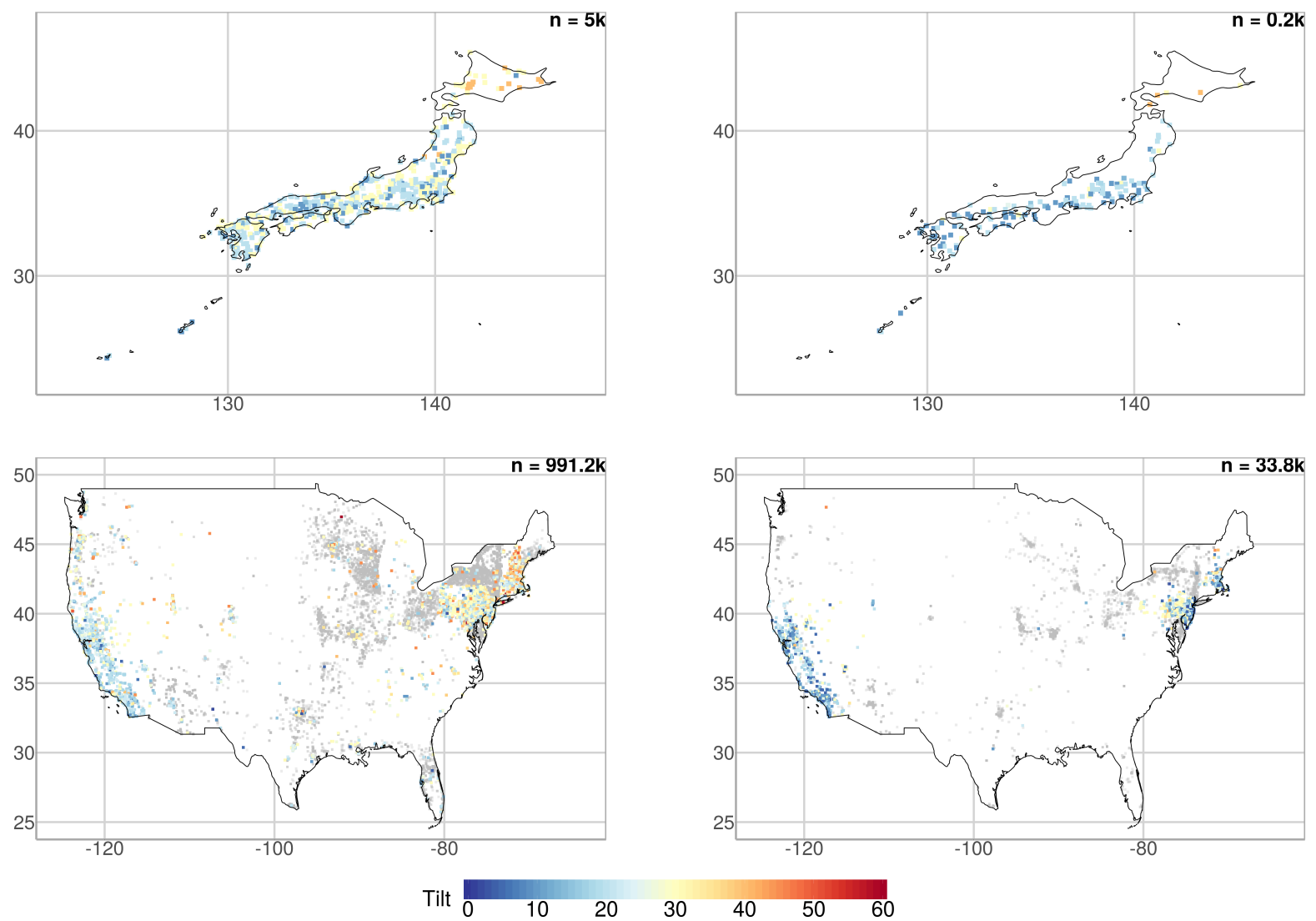

Figure 4: Maps for Japan (top) and the USA (bottom). The left column shows systems $\leq 25 \mathrm{kWp}$ and the right column systems $>25 \mathrm{kWp}$. Systems which do not report tilt are in grey colour.

in France leads to a high number of $3 \mathrm{kWp}$ systems 706 (see Leloux et al. (2012b) in section 1.1). In Ger- 707 many, there are changing regulations and feed-in 708 tariffs for systems $>30 \mathrm{kWp}$ resulting in an in- 709 crease in the black line of the right plot in Figure 2. 710 Furthermore, the UK had a higher feed-in tariff for 711 systems $\leq 4 \mathrm{kWp}$ up until January 2016 and has 712 since moved to $\leq 10 \mathrm{kWp}$ (ofgem, 2018). These are 713 such examples of significant policy-specific regional 714 influence that can impact upon the characteristics 715 of PV systems.

There are many opportunities as to how we sub- 718 categorise the data into clusters. Many of which could be explored in order to derive meaningful information depending on the approach. Options include separating by climatic region or grouping by policy similarities. However with respect to the aforementioned aspects, a clustering at a country level seems advisable for the following reasons: (1) National regulations and incentives have a visually evident impact on the occurrence of different system sizes which may itself influence other metadata. (2) A geographical influence was observed on multiple parameters. Countries limit this influence by their size. The only exception of this strategy is the USA. The enormous geographic area of this country 
results in a inhomogeneous pattern of the specific annual yield. This is a direct consequence of the heterogeneity of the solar resource within a country. The USA was thus split at $37.5^{\circ} \mathrm{N}$ into a northern and a southern component. The same approach could be applied to Australia, however, the sample size of available data is too low. Further subdivisions e.g. by the latitude for systems $\leq 25 \mathrm{kWp}$ in France (see tilt in Figure 4), could be considered but exceed the scope of this paper and is a focus of future work. (3) There is a certain convenience to clustering by countries. Many of the studies previous focused mainly on a single country, this is indicative of a researchers interests and data availability. We feel that, whilst there are many options of clustering that can be explored, a preliminary study at a country level is of most interest.

The region "Rest of Europe" is not be considered further due to its inhomogeneous portfolio of systems across different countries in Europe. The clusters, defined by their belonging to a region and system size, are used in the next section to derive representative distributions for the metadata. 

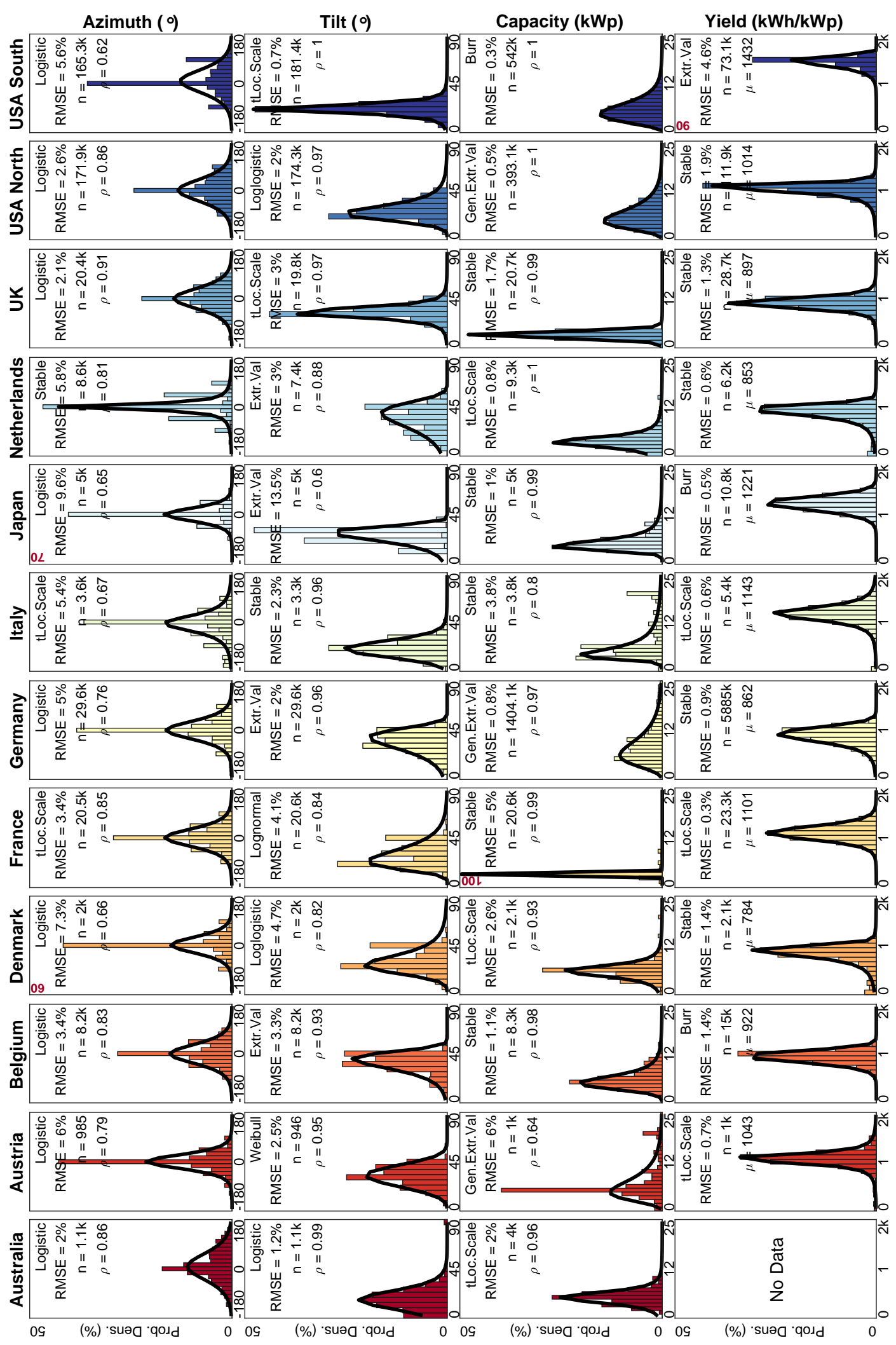


\section{Approximation of parameters in clusters}

The intentions of parametrisation are twofold Firstly, we want to discover whether or not the parameters (tilt, azimuth, capacity and yield) can be represented with simple parametric distributions. Secondly, we want to explore the relative differences between clusters through comparison between probability distributions. We concede that simple distribution fitting has weaknesses such as not appropriately capturing a more complex relationship offered by non-parametric fitting, however, reproducibility of the statistics is encumbered with added complexity. For our first presentation of the substantial volume of PV system data collected, we focus on simple distribution fitting as interesting comparisons and individual cluster insights can be drawn, and we are able to comment on the ability for these complex parameters to be represented as such.

\subsection{Methodology of fitting the distributions}

In order to enable the utilisation of the aggre- ${ }_{797}$ gated statistics of each cluster (defined in sec- 798 tion 3.2) and for each parameter (defined in sec- 799 tion 3.1), individual distributions are fitted to the 800 real-world probability density histograms. The re- ${ }_{801}$ sults are presented in Figure $5(\leq 25 \mathrm{kWp})$ and Fig- 802 ure A.10 (> $25 \mathrm{kWp})$. The total number of avail- ${ }_{803}$ able data varies between clusters and parameters; 804 there is no further processing beyond the criteria ${ }_{805}$ described in section 2; all possible data available ${ }_{806}$ is used. Differences in data within a cluster are due to some PV sites not reporting one or more parameters. There are up to 6 years of reported specific annual yield (2012-2017). The normalised value within each year is taken as an individual sample and so there are up to $6 n$ more samples for this parameter.

For each cluster and for each parameter, many different distribution types were fitted to the probability density. Distributions were fit using the inbuilt FITDIST function of the software Matlab®(Matlab, 2018). There are 23 parametric distribution types available, of which all are fitted to the data. Where distribution types require only positive values (for parameters with negative bins) or values between 0 and 1 , the data is scaled to satisfy the distribution requirements and allowed to rescale so that as many distributions could be tested; note that no distribution requiring this treatment was found to be best fitting, and so no further discussion is made regarding this normalising process. Probability density functions are then scaled to only exist between the $\mathrm{x}$-axes limits as indicated in the figure, for example, the tilt distributions are only relevant between $0^{\circ}$ and $90^{\circ}$. This means that the sum of all probabilities between the prescribed $\mathrm{x}$-axis range must be equal to 1 . This is important as some distributions facilitate values way outside of the bin limits resulting in the sum of probabilities between the bins of interest $\neq 1$, and so would not fit the histogram. The disclaimer is, therefore, that these distributions must be scaled before use and not be extrapolated beyond the specified bin ranges else risk persisting an under/overestimation about the scaling factor, defined as

$$
s=\frac{1}{\sum_{a}^{b} p_{a: b}},
$$


where $s$ is the scaling factor, $p$ is the probability at each bin between the lower and upper bin limit, $a$ and $b$, respectively. The resultant fitted distribution is then plotted against the real probability density and tested for linear fit; the root mean squared error (RMSE, percentage) and Pearson correlation coefficient ( $\rho$, dimensionless) are derived. A perfectly fitted distribution would result in $y=x$ with $\rho=1$ and an $\mathrm{RMSE}=0 \%$. The distribution type with the lowest RMSE was selected for the plot. Should there be more than one distribution type that has the same RMSE, then the type with lowest $\rho$ is selected. Should there still be more than one distribution type after this, one of the remaining types is selected at random.

The exact parameterisation for each distribution ${ }^{841}$ presented in Figure 5 and Figure A.10 are detailed ${ }^{842}$ in Table A.4. Each distribution has up to 4 co- ${ }^{843}$ efficients and are employed using different equa- 844 tions, not all 23 parametric distributions are de- 845 tailed, only those that featured within the study. 846 Whilst Table A.4 details the parameterisation of ${ }_{847}$ the coefficients, it is Table A.3 that explains how ${ }_{848}$ to use those values to form the distribution. Fur- 849 thermore, the mean or median values of the whole dataset, exclusive of the $25 \mathrm{kWp}$ separation, are ${ }^{850}$ presented in Table 2 .

\subsection{Discussion of the distributions}

The following discussion about clusters and dis- 854 tributions mainly refers to Figure 5 with systems 855 $\leq 25 \mathrm{kWp}$ unless explicitly noted otherwise. The ${ }_{856}$ reason for this is that the vast majority of systems ${ }^{857}$ are within the $\leq 25 \mathrm{kWp}$ category, and so are of ${ }_{858}$ most interest. However, important differences to 859
Table 2: Mean or median value extracted from entire data set (without separation by capacity size) for each of the parameters of tilt angle, azimuth angle, system capacity and specific annual yield.

\begin{tabular}{|c|c|c|c|c|}
\hline Country & $\begin{array}{l}\text { Tilt } \\
\left({ }^{\circ}\right) \\
\text { mean }\end{array}$ & $\begin{array}{l}\text { Azi. } \\
\left({ }^{\circ}\right) \\
\text { mean }\end{array}$ & $\begin{array}{c}\text { Cap. } \\
(\mathrm{kWp}) \\
\text { median }\end{array}$ & $\begin{array}{c}\text { Yield } \\
(\mathrm{kWh} / \mathrm{kWp}) \\
\text { mean }\end{array}$ \\
\hline Australia & 16.1 & 8.58 & 5.00 & - \\
\hline Austria & 31.1 & -0.34 & 5.15 & 1,040 \\
\hline Belgium & 35.6 & -1.69 & 5.20 & 921.5 \\
\hline Denmark & 30.0 & 0.48 & 6.00 & 786.0 \\
\hline France & 28.7 & -0.28 & 2.96 & 1,101 \\
\hline Germany & 31.6 & -2.46 & 8.96 & 870.2 \\
\hline Italy & 19.8 & -15.9 & 5.88 & 1,142 \\
\hline Japan & 23.8 & -1.20 & 4.92 & 1,222 \\
\hline Netherlands & 32.5 & 0.77 & 3.30 & 855.2 \\
\hline UK & 31.8 & -1.07 & 2.94 & 896.7 \\
\hline USA North & 25.2 & 0.42 & 5.81 & 1,005 \\
\hline USA South & 19.9 & 9.33 & 5.26 & 1,426 \\
\hline
\end{tabular}

system sizes $>25 \mathrm{kWp}$ are mentioned and can be observed in Figure A.10.

It is important to note that only rough dependencies between parameters, regions and system sized can be considered with this clustering approach. The more intricate and established interdependencies have not been explored within this paper as it is beyond the scope of the initial objective. The authors reserve this for future work.

\subsubsection{Azimuth angle}

The most noticeable feature of the azimuth obtorial facing PV system. This is unsurprising as it offers the best annual specific yield by receiving maximum system efficiency at peak solar position. The topic of extreme probability of an equatorial orientated system was discussed in section 3.1; the prevalence of $0^{\circ}$ is true of all sites for both $<25$ and $>25 \mathrm{kWp}$. The Japan and Netherlands clusters 
have exaggerated angles of $-45^{\circ}$ or $+45^{\circ}$, assumed 894 to be a result of overly simplified reporting.

The distributions could not capture the probabil- 896 ity of $0^{\circ}$ with exception of the Netherlands where 897 a Stable distribution fitted best. Even with large 898 sample sizes for the USA North and south clusters, 899 a distribution could not be fitted that satisfied the 900 observed probability for an azimuth angle of $0^{\circ} .901$ Perhaps a more complex or bespoke distribution 902 type is needed to suitably express the probability 903 distribution of azimuth angle with reproducible ac- 904 curacy. This large proportionality of $0^{\circ}$ was also 905 observed by Saint-Drenan et al. (2018), who fitted 906 a normal distribution in similar magnitudes to the 907 logistical distribution fitted in this article. That 908 said, there is an argument that the significant $0^{\circ}$ az- 909 imuth feature is exaggerated when considering the 910 UK cluster. The majority of the data within the UK 911 cluster is from Sheffield Solar. Their users report 912 the system metadata, however, there is a feedback 913 to the user reporting system performance analysis 914 on a monthly basis, inclusive of a nearest-neighbour 915 performance analysis of a system of similar meta- 916 data. Users are encouraged to verify their reported 917 metadata and is often double checked with satellite 918 imagery; the result is much more accurate report- 919 ing of metadata for the UK cluster leading to the 920 smoothness of distribution fit. With improved PV ${ }_{921}$ system metadata reporting, we see a wider spread 922 of azimuth about $0^{\circ}$.

\subsubsection{Tilt angle}

The tilt angle across all clusters is rather unique 926 per cluster with 7 different distribution types be- ${ }_{927}$ ing found as the best fitting among 10 clusters. We ${ }_{928}$ previously discussed the gentle increase of tilt angle with latitude. Solar installers can mount the PV panels with a steeper tilt angle to that of the roof at higher latitudes through arrangement of the mounting brackets; this is not expected to be overly common practise. The predominant factor for smaller roof integrated systems is expected to be the physical roof angle, which is influenced by local architectural styles. We suspect this is the case, particularly when considering France in Figure 3 where there exists a distinct change in the tilt for the $\leq 25$ kWp systems at roughly $47.5^{\circ}$ latitude. Note that France and Denmark have similar distributions despite France having a significant number of systems south of that $47.5^{\circ}$ roof tilt feature. Furthermore, Belgium and the Netherlands share similar climate and latitude yet feature distinctive distributions.

Interestingly, the Australian cluster consisting of the second lowest number of observations has the second most accurate fit after USA South. This is in part due to the smoothness of the distributions and accuracy of method in which the tilt is obtained (see section 2). The USA cluster has excellently fitted distributions suggesting accurate measurement, particularly for the USA South cluster where the tilt distribution is fitted with $\rho=1$ and RMSE $=0.7 \%$. The Japan cluster evidently suffers from reporting to the nearest $10^{\circ}$, and so we suggest to avoid using a best-guess approach to collecting metadata as it leads to biased distributions. The tendency for larger system sizes having smaller tilt angles, introduced in section 3.1, can be confirmed when comparing Figure 5 and Figure A.10. The only exception is Denmark, which reports only a small number of systems $>25 \mathrm{kWp}$. 
Within the distributions, the smallest mean tilt 963 angles were reported in Australia (16.07), Italy 964 $\left(19.81^{\circ}\right)$ and USA South $\left(19.89^{\circ}\right)$. The largest 965 mean tilt values were reported in Belgium (35.58 $) 966$ and closely followed by the UK, Germany and Aus- 967 $\operatorname{tria}\left(31^{\circ}\right)$

\subsubsection{Installed capacity}

The most obvious observation from the installed 971 capacity is the extreme peak within the French clus- 972 ter. Of all $20.6 \mathrm{k}$ systems $(\leq 25 \mathrm{kWp}$ and $>25973$ $\mathrm{kWp}), 73.74 \%$ of them report an installed capacity 974 of $3 \mathrm{kWp}$ when rounded to nearest integer, though 975 note that the French dataset reported to a high dec- 976 imal precision. The best fitting distribution cannot 977 appropriately represent this extreme despite a very 978 high $\rho=0.99$; the RMSE value of $5 \%$ is indicative 979 of the Stable distribution assigning $100 \%$ probability to $3 \mathrm{kWp}$. This distribution is, therefore, very 980 limited even if it does most accurately capture the 981 data for France. As discussed when defining the 982 clusters, this peak in capacity is a direct response 983 to regulations within that country. This is further 984 observed in the UK database, with the vast major- 985 ity of systems being $\leq 5 \mathrm{kWp}$ due to the nature of ${ }_{986}$ the feed-in tariff rate. The north and south USA ${ }_{987}$ clusters demonstrate the power of a larger and con- 988 sistent sample size reporting RMSE $0.5 \%$ and $0.3 \%$, 989 respectively, with both reporting $\rho=1$. Interest- 990 ingly, the distribution type between USA clusters 991 are distinct from each other, with a slightly in- 992 creased probability of smaller systems in the south. 993 This is expected to be a result of more rooftop solar 994 in the sunnier States, though this is speculation. 995 The shape of the distribution functions for sys- 996 tem sizes $>25 \mathrm{kWp}$ (Figure A.10) differ to systems $\leq 25 \mathrm{kWp}$ and show an heightened concentration of systems $<50 \mathrm{kWp}$. Australia is an exception and reports many systems with an installed capacity of $\approx 100 \mathrm{kWp}$.

The mean values of capacity are too heavily influenced by the presence of large systems (cf. 2b), and so the median value is reported to reduce bias. From the distributions, the country with smallest capacity median is the UK $(2.94 \mathrm{kWp})$ and the largest is Germany $(8.96 \mathrm{kWp})$. The fact that the German data reveals such a high median is reflective of the thorough nature of data collection whereby nearly all systems are reported; we have very few large systems reported from the UK as the database is primarily used for rooftop solar and so this statistic is not overly representative.

\subsubsection{Specific annual yield}

The most noticeable detail of the specific annual yield distribution fits is the smoothness of the histograms of raw data. This is perceived to be of two reasons. Firstly, the sample size is typically much larger $(n=5.885 \mathrm{~m}$ for the German cluster). Secondly, the data is digitally recorded and not reliant on human reporting. The mean $\mu$ is presented in place of the correlation coefficient so as not to over busy the plot, though for completeness, all sites reported $\rho \geq 0.98$ except USA South with $\rho=0.93$. Recall that the specific annual yield is normalised for inter-annual differences and so we can directly compare clusters. Each cluster exhibits reasonably unique subtle traits, it is expected that the larger the share of equatorial orientated systems with more optimal tilts, the larger the specific yield, 
however, it is also a function of local meteorology 1032 and climate local to the systems and not just lat- 1033 itude, orientation and tilt. More questions can be derived from these distributions than are really an- ${ }^{1034}$ swered. For example, consider the German cluster. 1035 There is a substantial tail towards lower specific 1036 annual yields that is not observed in other clusters. 1037 Germany is known to be a mature market when it 1038 comes to PV, and so is this tail indicative of age- 1039 ing systems, or perhaps all clusters would present 1040 this pattern given as large a sample size? The USA 1041 South cluster has an unexplainable peak at exactly 1042 $1650 \mathrm{kWp} / \mathrm{kWh}$. The only other country within our 1043 study that is comparable to southern USA in terms 1044 of climate and land availability is Australia, alas, 1045 we have no data for this cluster to gain insight to 1046 this peak. We would expect to observe much higher 1047 yields in Australia akin to southern USA.

Leloux et al. (2012a) found that of 158 sys- 1049 tems in Belgium,the mean specific annual yield was 1050 $836 \mathrm{kWh} / \mathrm{kWp}$. Our analysis of $15 \mathrm{k}$ specific an- 1051 nual yields finds the mean to be $921.5 \mathrm{kWh} / \mathrm{kWp} .1052$ Leloux et al. (2012b) applied the same approach 1053 for 1,635 systems in France resulting in a mean of 1054 1,163 kWh/kWp. Our analysis of 23.3k systems 1055 places the mean value at 1,101 kWh/kWp. When 1056 comparing Figure 5 and Figure A.10, the expected 1057 trend towards higher specific annual yield values for 1058 larger systems (see section 3.1) can be confirmed for 1059 Denmark, France, Germany, Japan, Netherlands, 1060 UK and USA North. The other four countries in- 1061 stead show a decrease in the mean specific annual 1062 yield for systems $>25 \mathrm{kWp}$.

From the distributions, we find the smallest 1064 mean specific annual yield is in Denmark (786.0 ${ }_{1065}$
$\mathrm{kWh} / \mathrm{kWp})$ and largest in USA south $(1,426$ $\mathrm{kWh} / \mathrm{kWp})$.

\subsection{Using the distributions}

As we have observed that each cluster and parameter can be generally represented by a probability distribution, our discussion can shift towards the usage of these statistics in regional PV power modelling approaches. Generally, the cited publications in section 1.1 (category 1) not only emphasize the practical relevance of statistical distributions in regional PV power modelling approaches, but also sketch the procedure of how these statistics can be used and therefore serve as good examples. One of these publication is Saint-Drenan et al. (2018), which provides detailed information about how fitted distributions can be applied in a regional power simulation and therefore serves as a good example.

We foresee that the fitted distributions from the previous section can be used to randomly sample the desired metadata of a portfolio of systems in a specific cluster. As pointed out in section 3.2, this cluster can then be weighted individually by the probability of occurrence (as can be derived e.g. from Figure 2. To reproduce the distributions, one must extract the appropriate distribution variables from Table A.4, apply them in the expression from Table A.3, and scale the result according to Eq. (1). We state that the data we have is not representative enough to derive global distributions as there are too many features that can influence the PV system characteristics from regions we do not have access to. The derived distribution functions should only be used for their specific clusters, or for clusters with particularly similar climates and policies. 
The usage of the fitted distributions is sketched 1101 in a practical example, assuming that the PV power 1102 generation in Germany is of interest.

1) In Germany, the installed capacity, geographic 1104 location and specific annual yield of all PV systems 1105 is known (see section 2) and should not been sam- 1106 pled if one wishes realistic outputs, though may be 1107 sampled for theoretical purposes.

2) For each PV system, tilt and azimuth is as- 1109 signed by sampling the fitted distribution from the 1110 relevant cluster. E.g. a system with $10 \mathrm{kWp}$ will 1111 use the distributions from the cluster for systems $\leq{ }_{1112}$ $25 \mathrm{kWp}$. In this example we can extract the data 1113 from Table A.4 such that the German cluster has a 1114 Logistic distribution for azimuth with location co- 1115 efficient of -0.1366 and scale parameter of 20.6455. 1116 The distribution can be recreated using the logis- 1117 tic function defined in Table A.3. Please note that ${ }_{1118}$ there is a high risk that the sampled characteristics 1119 won't accurately predict the metadata for a specific 1120 PV system. It is the objective to use these distribu- ${ }_{121}$ tions to simulate larger PV portfolios and we expect 1122 to derive representative characteristics for that ap- 1123 plication.

3) The direct usage of yield is more complicated 1125 for two reasons. Firstly, in contrary to azimuth, tilt 1126 and installed capacity, it is not an input param- 1127 eter in the simulation chain but instead indicates 1128 the power generation, which is the typical output 1129 of a simulation. Secondly per definition, the spe- 1130 cific annual yield sums the PV power generation ${ }_{131}$ over a whole year. In many application however, ${ }_{1132}$ simulations may cover a different time span. How ${ }_{1133}$ can yield be used in simulating the regional PV ${ }_{1134}$ power generation then? When making the simplify- 1135 ing assumption that the meteorological conditions are relatively similar within a cluster, the observed specific annual yield can be interpreted as a measure that expresses relative performance differences between PV systems. For instance, a PV system with a yield of $600 \mathrm{kWh} / \mathrm{kWp}$ can be said to be less efficient than a PV system with a yield of 800 $\mathrm{kWh} / \mathrm{kWp}$. For usage in a simulation, a conversion from yield into an performance factor is therefore necessary. A potential method of conversion is to take the range of yields ( 0 to $2000 \mathrm{kWh} / \mathrm{kWp}$ ) and align it to typical ranges of the performance ratio, though taking care to centre the mean yield against the mean performance ratio (said to have a wide distribution centred about 0.74 as derived from 5,000 systems in the Netherlands (Tsafarakis et al., 2017; Reich et al., 2012)). A direct linear conversion could then be applied. For example, a system in Germany with yield $870.2 \mathrm{kWh} / \mathrm{kWp}$ (the mean for this cluster) could be assigned a performance ratio of 0.74 . This performance ratio can then be applied as a correction factor to either the output power or the system capacity, and therefore facilitating representative differences between systems.

4) The individual PV power generation for each system can be simulated by considering the sampled system characteristics as well as the known installed capacity, efficiency of the specific system and its geographic location. Within such a simulation, other inputs will be needed such as the local irradiance or ambient temperature. Please note, if considering such a large number of systems is too computational intense, instead a smaller number could be randomly chosen and then used within an upscaling 
approach.

5) Finally, the total power in Germany can then 1170 be derived by aggregating the simulated power from ${ }_{1171}$ all systems.

\section{Shading on roofs}

\subsection{Methodology of the shading analysis}

An objective in this paper is to derive gener- ${ }^{1176}$ alised findings of how to consider the impact of ${ }^{1177}$ shading. We aim to achieve that in a more so- ${ }^{1178}$ phisticated manner than the overly simplified man- ${ }^{1179}$ ner presented in category 3 from section 1.1. It is, ${ }^{1180}$ however, not the aim to study differences of shad- ${ }^{1181}$ ing in rural or urban areas all over the world in ${ }^{1182}$ this paper. This shading analysis is performed on ${ }^{1183}$ $\approx 48,000$ buildings in the city of Uppsala, Swe- ${ }^{1184}$ den $\left(\mathrm{N} 59.9^{\circ}, \mathrm{E} 17.6^{\circ}\right)$. Uppsala provides a variety ${ }^{1185}$ of different buildings (44\% residential, $2.2 \%$ indus- ${ }^{1186}$ tries, $5.7 \%$ commercial and services, $49 \%$ other) and ${ }^{1187}$ therefore allows studying differences in the impact ${ }^{1188}$ of shading. The average height of the buildings ${ }^{1189}$ studied here are $6.4 \pm 4.1 \mathrm{~m}$, which may be com- ${ }^{1190}$ pared to a study on 12 US cities of various size 1191 (29,498 to $1,066,354$ buildings) with average build- 1192 ing height ranging from 4.1 to $9.7 \mathrm{~m}$ (Schläpfer ${ }^{1193}$ et al., 2015). The analysis is not limited to any ${ }^{1194}$ country specific influences because all combination 1195 of solar angles are considered; climate does not in- 1196 fluence this shading study. The above reasons em- 1197 phasise the general representativeness of Uppsala 1198 and were reason for its selection.

The shading analysis is realised by using the 1200 method in Lingfors et al. (2017), which was cross- 1201 validated in Lingfors et al. (2018). Inputs to 1202 the model are low-resolution LiDAR data (0.5-1 $\mathrm{pts} / \mathrm{m}^{2}$ ) and building footprints, provided by the Swedish Land Survey $(2015,2016)$. The model does the following:

1. Finds a simple roof shape from a template of roof types using linear regression on LiDAR data;

(a) within the footprint of the examined building and,

(b) within building footprints of similar shape in its proximity,

2. Each roof now consists of 1-4 facets depending on the roof type ( 1 for flat or shed, 2 for gabled and 4 for hipped or pyramidal). If LiDAR data are insufficient, the roof type cannot be determined and the building is excluded from further analysis. The number of roof facets are $>90,000$ (cf. number of buildings). However, around 1,000 facets which are $>20 \mathrm{~m}$ above ground are excluded, as there is an increased risk of these roofs being misrepresented due to noise in the LiDAR data.

3. After some filtering of the LiDAR data surrounding the building, a triangulated irregular network (TIN) is produced representing objects, predominantly trees and other buildings that may shade the roof.

4. Using the TIN as input, a viewshed (a map showing what parts of the sky are visible from the perspective of a point on the roof) at every $0.5 \mathrm{~m} \times 0.5 \mathrm{~m}$ section of the roof is calculated to determine whether there are objects blocking the direct solar path. The resolution of the viewshed is limited to solar elevation angles, 
$\alpha_{s}$, of $2.5,7.5, \ldots, 87.5^{\circ}$, and solar azimuth angles, $\gamma_{s}$, of $-180,-170, \ldots, 170^{\circ}$ where $0^{\circ}$ is due south. Since the sky sectors are angular-equal, they are not equal in size (see dotted lines in Figure 6). Hence, the contribution of diffuse irradiance from each sky sector depends on its size and the angle-of-incidence of the irradiance from the sky sector onto the plane.

5. For each combination of $\alpha_{s}$ and $\gamma_{s}$ the mean shading of the whole roof facet is calculated, noting that roofs can be partially shaded. This is illustrated in the viewsheds of Figure 6. For a discrete point of the roof, each element of the sky would be either shaded or not shaded corresponding to black or white (0 or 1 ), respectively, in the left panel of Figure 6. However, if the mean of all points of the roof are considered, the viewshed would be blurred (grey) as illustrated in the right panel of Figure $6 .{ }^{1237}$ The mean viewshed displayed on the right of ${ }^{1238}$ Figure 6 is only for illustrative purposes and ${ }^{1239}$ can be considered to gain understanding as to ${ }^{1240}$ how the beam, diffuse and reflected irradiance ${ }^{1241}$ subcomponents are affected by shading for the ${ }^{1242}$ general region of all facets within this study. ${ }^{1243}$ Results of the shading analysis are presented ${ }^{124}$ in section 5.2 .

\subsection{Deriving a simplified shading model}

The main results from the shading analysis on 1249 $\approx 48,000$ buildings in Uppsala, Sweden, are pre- 1250 sented in Figure 7. The colour of each bin in the ${ }_{1251}$ left panel of Figure 7 represents the average ratio of ${ }_{1252}$ all roof facets being visible to a sky sector, defined ${ }_{1253}$
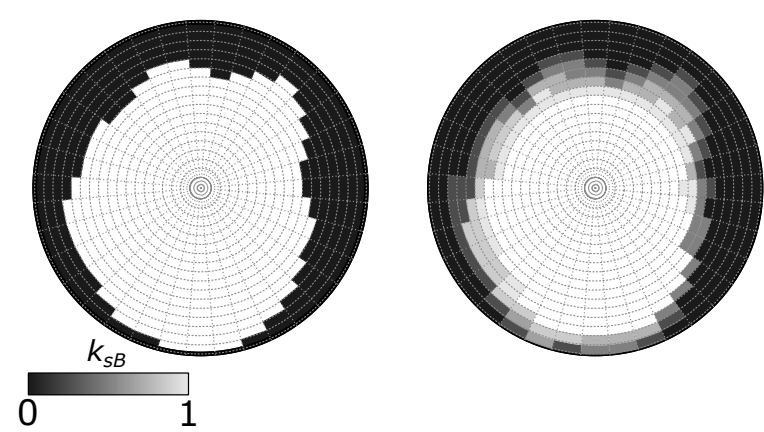

Figure 6: Polar diagrams of viewsheds, where the displayed angles represent the azimuth angle, and the radius the elevation angle. Left) illustrates the viewshed of a single point on the roof. Right) the mean viewshed of all the points on the roof is illustrated. The dotted lines mark the sky sectors for which the viewshed analysis was conducted from their respective centre points. Note that the right plot is purely illustrative and not used within any of the modelling stages.

by the corresponding solar elevation angle and solar azimuth intervals. This visibility is here referred to as the beam shade index, $k_{s B} \in[0,1]$ (see Figure 6), where 0 means the roof facet is fully shaded. The dashed lines illustrate the solar path for Uppsala, Sweden. However, the corresponding solar path could be over-layered for an arbitrary site to visualise the implication of shading for that site. From the left panel of Figure 7 it is also clear that the solar azimuth has very little importance, which is logical as shading should be as likely from any direction when a large portfolio of buildings is considered.

In the right panel of Figure 7, the average $(x-$ marked) and percentiles (dashed) of $k_{s B}$ for all roofs are presented as a function of only the solar elevation angle, hence it differs from the left panel by not considering the azimuth angle. The thin red lines 

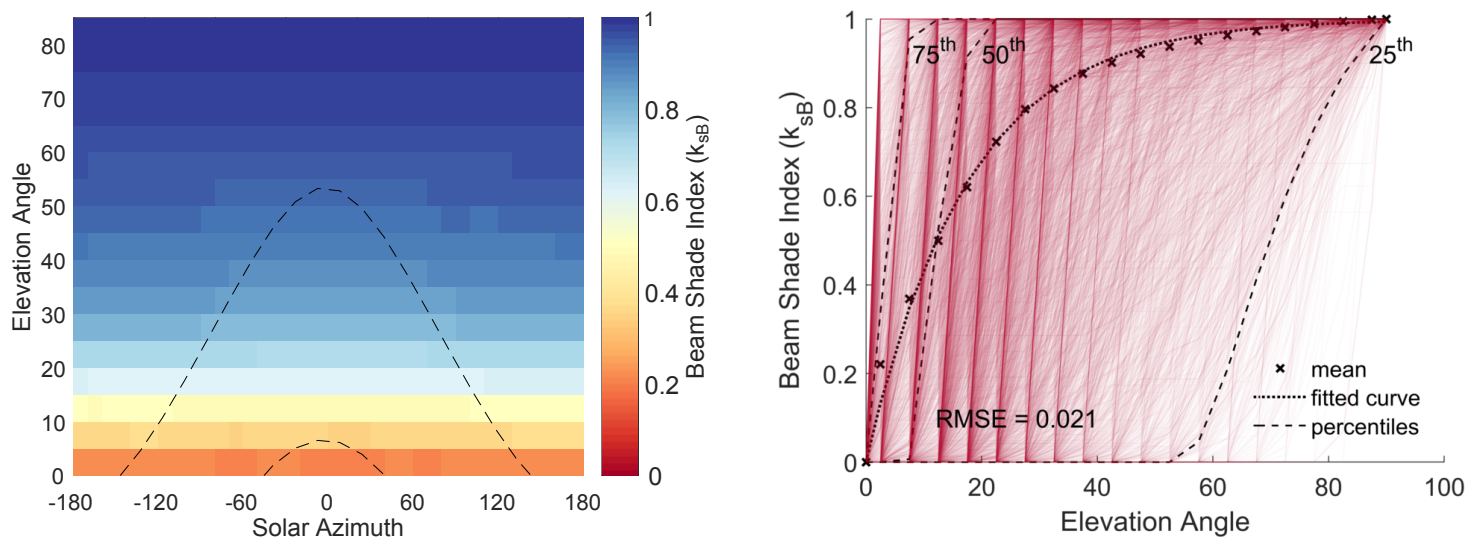

Figure 7: To the left, the mean shade index of all studied roof facets are presented at bins of a viewshed defined by the solar elevation angle and solar azimuth. To the right, the shade index is plotted against the solar elevation angle. Every shade index profile from each studied facet are indicated with a red solid line. The mean shade index of all facets is indicated with crosses, with fitted curve represented by a dotted line as presented in Eq. (2). The RMSE between the means and fitted curve is 0.021 . The dashed lines represent the different percentiles.

represent 10,000 individual roofs. Many of these 1269 lines jumps from 0 to 1 when going from one ele- 1270 vation angle to the next, meaning that from being ${ }_{1271}$ entirely obscured, the roof becomes entirely visible 1272 when the elevation angle is increased by $5^{\circ}$. The ${ }_{1273}$ mean beam shade index, $\bar{k}_{s B}$, of all the roof facets 1274 can be represented by a fitted curve (dotted), de- 1275 rived as a function of the solar elevation angle, $\alpha_{s}: 1276$

$$
\bar{k}_{s B}=1-e^{-\alpha_{s} / 17.5} .
$$

The average beam irradiance that will fall on a tilted roof, if shading is considered, could then be calculated as:

$$
B_{T}=\bar{k}_{s B} \frac{\cos \theta}{\cos \theta_{Z}} B_{H},
$$

where $B_{H}$ is the unshaded beam irradiance on the 1285 horizontal plane, $\theta$ is the angle between the incident 1286 irradiance and the normal of the roof plane and $\theta_{Z}{ }_{1287}$ is the solar zenith angle.
Assuming similar shading properties, i.e., vegetation and urban density, as in Uppsala, this function may be used in any area to determine the impact of shading on roofs as a function of the solar elevation angle. It gives a better estimation than solely assuming a cut-off solar elevation angle for the beam irradiance, which is a method commonly used for PV potential studies.

On the other hand, the red lines of figure in the right panel, representing individual buildings, reveals the variation in shading among the buildings. Thus, studies of higher detail where, for instance, the implications in a low-voltage grid due to shading on PV modules are studied require a method that reproduces these variations.

If the global irradiance on a shaded roof is of interest, one also needs to consider the diffuse $\left(D_{T}\right)$ and reflected $\left(R_{T}\right)$ irradiance subcomponents on the tilted plane, which both depend on the view factor (visible fraction of the sky, $f_{s k y} \in[0,1]$ ) from 


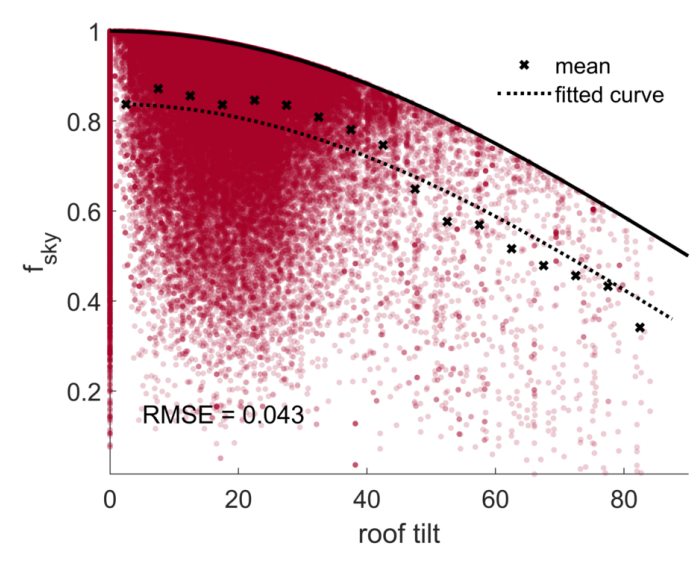

Figure 8: The mean $f_{s k y}$ as a function of the roof tilt (marked with $\mathrm{x}$ ) and a fitted curve (dotted) presented in ${ }^{1318}$ Eq. (4). The solid line represents the first term of Eq. (4) 1319

the perspective of the roof. I.e., the viewshed of the roof should be considered (see Figure 6). The view factor $f_{s k y}$ represents the ratio of the isotropic diffuse irradiance from the sky hemisphere and reaches a value of 1 for a horizontal surface if there are no shading objects.

The values of $f_{s k y}$ for $>90,000$ studied roof ${ }^{1322}$ facets are presented in Figure 8. A fitted curve ${ }^{1323}$ (with an RMSE of 0.043 with respect to the means, ${ }^{1324}$ indicated by black crosses) was derived with the ${ }^{1325}$ function:

$$
\bar{f}_{s k y}=\frac{1+\cos (\beta)}{2}-C,
$$

where the first term is the view factor for a free sky ${ }_{1330}$ and $C$ is a constant representing the contribution ${ }_{1331}$ from shading objects, here found to be 0.162 . This ${ }_{1332}$ equation may be used to calculate the diffuse and ${ }_{1333}$ reflected irradiance following equations (6) and (10) 1334 in Lingfors et al. (2017), respectively.

In Figure 9 the losses due to shading are pre- 1336 sented for the three irradiance subcomponents (cal- ${ }_{1337}$ culated individually for each roof facet), sorted with respect to decreasing diffuse irradiance losses. In this analysis, hourly instantaneous Global Horizontal Irradiance (GHI) and Direct Normal Irradiance (DNI) data from 2014 for Uppsala were used (SMHI, 2015). $B_{T}$ was calculated through Eq. (3), if we let $\bar{k}_{s B}$ here represent the mean value of $k_{s B}$ for all points on the individual roof facet. $D_{T}$, as well as $R_{T}$, were calculated through equations (6) and (10) in Lingfors et al. (2017), respectively, using the $f_{\text {sky }}$ derived for each roof facet. These equations, adapted for the conventions used in the present paper, can be expressed as:

$$
D_{T}=D_{H}\left[\left(1-A_{i}\right) f_{s k y}+\frac{\cos \theta}{\cos \theta_{Z}} A_{i}\right],
$$

and

$$
R_{T}=\left(B_{H}+D_{H}\right) \rho\left(1-f_{s k y}\right),
$$

where $A_{i}$ is the anisotropy index and $\rho$ is the surface albedo, here assumed to be 0.2 for all surfaces (i.e., ground, trees, buildings etc.).

Hence, Eqs. (2) and (4) in the present paper were not used here, but could be valuable in future studies where, for instance, the level of detail of the building topography in a city is unknown or the time for making detailed simulations is limited, yet the impact of shading on solar power generation is of interest." The in-fold figure illustrates the negative correlation between diffuse $\left(D_{T}\right)$ and reflected $\left(R_{T}\right)$ irradiance. The diffuse irradiance decreases (i.e., the losses increase) with a decreasing $f_{s k y}$, while instead the reflected irradiance increases (i.e., negative losses in Figure 9). From Figure 8, it is clear that $f_{\text {sky }}$ decreases with an increasing roof tilt, 
leading to a higher contribution of reflected irradiance for a highly tilted roof. The mean losses due to shading (expressed in relation to the unshaded global irradiance) for the whole building portfolio are $7.3 \%, 3.6 \%, 6.3 \%$ and $-2.7 \%$ for the global, beam, diffuse and reflected irradiance, respectively, where the minus sign is indicative of an added contribution to the total irradiance, since trees, buildings etc. adds to the total reflective area seen by the roof when shading is considered. Hence, diffuse losses contribute the most for Uppsala, which has an annual clear-sky index of 0.63 (calculated as the global horizontal irradiation for 2014 divided by the clear-sky irradiation for the same period (Ineichen and Perez, 2002)). One should also remember that all roofs in Uppsala were considered. If only roofs with installed PV systems on them were considered, the losses would most likely be lower. It is likely that the present method over-estimates the reflected irradiance at clear conditions as all trees and buildings seen by a roof could also be themselves shaded, therefore, offering reduced reflected irradiance. To consider this is a complex matter and needs extensive research. For instance ray-tracing could be incorporated in the model but at a computational cost.

\section{Future advancements beyond the scope of ${ }_{1383}$} this work

The main objective of the paper was to fit distributions to selected metadata and approximate functions that describe the impact of shading. This enables replication of these characteristics and allows a usage in regional PV power modelling ap- 1389

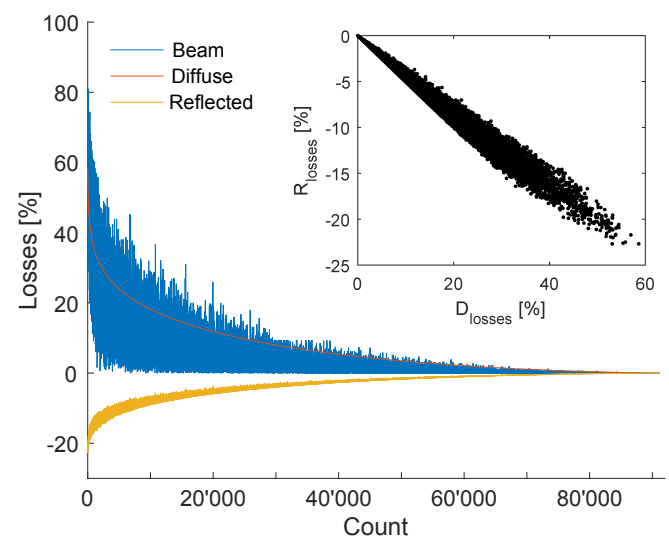

Figure 9: Beam and diffuse irradiance losses and the added contribution from reflected irradiance to the global irradiance considering shading on the $>90,000$ studied roof facets. The in-folded figure illustrates the negative correlation between the losses of diffuse and reflected irradiance when shading is considered. 
dataset offers so much information that it is im- 1424 possible to evaluate all specific parameters in detail within one paper. This data could potentially be used to study various performance indicators, e.g. by including irradiance information in specific regions and the age of the systems (provided for most systems).

- Dependencies between parameters: In ${ }_{1431}$ this paper we have qualitatively discussed pair- 1432 wise dependencies between parameters. Fur- 1433 thermore, we have applied a quantitative ap- ${ }^{1434}$ proach to individual parameters by fitting dis- 1435 tribution functions. The next step will be ${ }_{1436}$ to quantitatively incorporate dependencies be- ${ }^{1437}$ tween multiple (two and more) parameters, e.g. 1438 by joint distributions, multivariate models, etc. 1439 By that, the complex relations should be better represented.

- Complex distributions: The azimuth an- ${ }_{1442}$ gle presented irregularities with a wide base ${ }_{1443}$ and tall $0^{\circ}$ peak and on occasion presented ${ }_{1444}$ a trimodality that is certainly not-able to be 1445 captured by standard parametric distribution 1446 types with satisfaction. Whilst we dispute the ${ }_{1447}$ validity of much of the measured data due 1448 to reporting simplifications, there is scope to 1449 analyse the distributions in a more statistically 1450 rigorous manner. There is scope to combine ${ }_{1451}$ distributions and to enable multi-modal, non- 1452 parametric definition of the non-conformal pa- 1453 rameters, notably the tilt and azimuth. We ${ }_{1454}$ intend to make available the actual probability 1455 distribution for the reader to draw their own 1456 conclusions, see our invitation for collaboration ${ }_{1457}$ below.

- Cluster refinement: Influence of climatic region may influence certain parameters, particularly the specific annual yield. It is probable that the specific annual yield is not only a function of latitude (as we have demonstrated with a general regression between $30^{\circ}$ and $50^{\circ}$ of latitude), however, it is a function of the climatic region where those sites are situated. There is a lack of data within the $0^{\circ}$ to $30^{\circ}$ latitude band with which to successfully analyse this hypothesis. Further steps could be to replace the clusters by country with clusters by climate region using maps such as the Köppen-Geiger classifications, or perhaps by mean irradiance using a dataset such as NASA SSE.

- Shading: As mentioned in section 5.2 the results on shading from the present study can be used on a large portfolio of buildings, while for smaller areas one may want to produce realistic viewsheds for a few buildings to study the impact from shading. One simple approach would be to provide a database of viewsheds such as the one produced in this study, from which samples could be randomly drawn. To avoid the need of a database, another approach could be to design a model that can reproduce the distribution of shading profiles, perhaps stochastically using Markov chains to create statistically appropriate skylines. While the solar elevation angle is probably the most influential parameter, other factors such as the type of roof or height of the building would most likely also have an impact. Hence, a set 
of building specific parameters would satisfy as 1491 inputs to such a model.

\section{- Invitation for collaboration and data} access: This work would not have been possible without support from many sides mentioned in the acknowledgements. Gathering this data has proven difficult at times, and finding the correct person to approach was not straight forward. Therefore, we would like to extend an invitation to the reader. Should you have good ideas of how to use this data, or have large data itself, particularly in countries that we have not detailed, we encourage you to get in contact with either Sven Killinger (sven.killinger@ise.fraunhofer.de, svnkllngr@gmail.com), Jamie ${ }^{1500}$ Bright (jamie.bright@anu.edu.au, jamiebright1@gmail.com) or Nicholas Engerer (nicholas.engerer@anu.edu.au). Much of the data is confidential and so we cannot share it, however, the aggregated statistics are available. Should you wish to have access to the real distributions presented in the work, they are available on request, should they be publicly released, all communications will be made through our ResearchGate project. You are encouraged to follow that project for ${ }^{1}$ updates and communications (Bright et al., 2018).

\section{Summary}

Knowledge of PV system characteristics is needed ${ }_{1523}$ in the different regional PV modelling approaches ${ }_{1524}$ but are either unknown or only accessible for a small ${ }_{1525}$ number of stakeholders. The aim of this paper was to provide knowledge of PV system characteristics through data collection, analysis and distribution fitting of PV system characteristics. The structure presented was twofold and focused on (1) metadata (tilt and azimuth of modules, installed capacity and specific annual yield) as well as (2) the impact of shading.

We considered 2,802,797 PV systems located in Europe, USA, Japan and Australia, which represented a total capacity of $59 \mathrm{GWp}$ (14.8\% of installed capacity worldwide). Interdependencies of the installed capacity and the geographic location to the other parameters tilt, azimuth and specific annual yield were observed. To acknowledge the impact from these two dominating parameters (installed capacity and geographic location) on others and to allow a derivation of meaningful statistics, a clustering of systems on a country-basis with additional separation by systems sizes $\leq 25 \mathrm{kWp}$ and $>25 \mathrm{kWp}$ was introduced. For eased future utilisation of the analysed metadata, each parameter in a cluster was approximated by a distribution function. Results show strong characteristics unique to each cluster, however, there are some commonalities across all clusters. The smallest mean tilt values were reported in Australia $\left(16.1^{\circ}\right)$, USA South and Italy (19.8 and $19.9^{\circ}$, respectively). The largest mean tilt values were reported in Belgium $\left(35.6^{\circ}\right)$, the UK $\left(31.8^{\circ}\right)$ and Germany $\left(31.6^{\circ}\right)$. We find the smallest mean specific annual yield is in Denmark $(786.0 \mathrm{kWh} / \mathrm{kWp})$ and largest in south USA $(1,426 \mathrm{kWh} / \mathrm{kWp})$, this corresponds well to the climatic differences between 30 and $50^{\circ}$ latitude within the study. The region with smallest me- 
dian capacity was UK (2.94 kWp) and the largest 1561 was Germany (8.96 kWp). Almost all countries 1562 had a mean azimuth angle normal to the equa- 1563 tor. The number of equatorially-orientated sys- 1564 tems was significantly higher than any other ori- 1565 entation, such that no distribution type could ap- 1566 propriately capture this characteristic. That said, 1567 it is expected that the number of systems with az- 1568 imuth of $0^{\circ}$ are exaggerated due to lacking preci- 1569 sion of PV system metadata reporting, and per- 1570 haps the statistical distributions are more realistic 1571 than the data suggests, particularly when consid- 1572 ering the reduced peak from higher accuracy meta- 1573 data, such as that from the UK. Capacity demon- 1574 strated the most cluster-unique characteristics. As each cluster represented a country, it also captures 1575 national policy incentives that clearly influence the overall capacity distributions. The feed-in tariffs of ${ }^{1576}$ France, Germany and the UK have clear impact on the PV system size. The shape of the distributions of specific annual yield offered the most similarity 1578 between clusters, with the location/mean being pri- 1579 marily a function of climate through latitude. Dis- 1580 semination of clusters by climate may reveal more 1581 insightful differences. All of the distributions that 1582 are presented in the paper can be obtained from the 1583 tables in the appendix.

Shading was considered by computing the view- 1585 shed of individual roof facets of $\approx 48,000$ buildings 1586 in Uppsala, Sweden, which meant that > 90,000 1587 facets were analysed. Two empirical equations 1588 were derived and presented. The first represents 1589 the beam irradiance subcomponent, describing the 1590 mean ratio of a roof that is shaded as a function 1591 of the solar elevation angle. The second determines 1592 the view factor as a function of the roof tilt including the impact from shading and can be used to estimate the losses of diffuse and reflected irradiance. These equations are believed to better take shading into consideration than the coarse estimates used today. For the specific meteorological conditions of Uppsala, we also showed in this study that losses of diffuse irradiance due to shading are higher than that of beam on an annual basis and should not be neglected for sites of similar cloudiness as in Uppsala (annual clear-sky index of 0.63).

Several interesting research topics beyond the scope of this paper were sketched and the offer for future collaborations expressed.

\section{Conflict of interest}

The authors declare no conflicts of interest.

\section{Acknowledgement}

The authors would like to thank the Australian Renewable Energy Agency (ARENA) for supporting this work (Research and Development Programme Funding G00854). Part of this work is performed within the framework of the IEA-PVPSTask 13 "Performance and Reliability of Photovoltaic Systems" (IEA-PVPS, 2018). We would also like to acknowledge the Jyukankyo Research Institute Inc. and particularly Mr Takahiro Tsurusaki, Managing Director, COO, for the collaborative spirit shown and for the provision of data for Japan. The authors would like to thank those researchers that were approached who warmly invited the call for collaboration, however, were unable to contribute directly. Dr Joao Gari da Silva 
Fonseca Jr, Assistant Professor at the University 1626 of Tokyo, was invaluable in guiding us to the Japanese dataset. Rodrigo Palma-Behnke, Director and Assistant Professor of Solar Energy Re- ${ }_{1628}$ search Center, Universidad de Chile, was able to ${ }^{1629}$ provide the international collaborative effort with ${ }^{1630}$ large scale PV systems information within Chile ${ }_{1632}^{1631}$ that was unfortunately outside the scope of this ${ }_{1633}$ project. Dr Jan Kleissl, Professor at UCSD, USA, ${ }^{1634}$ for directing us to databases within the USA. We ${ }^{1635}$ would like to thank Dr Rodrigo Alonso Suárez of ${ }_{1637}^{1636}$ UDELAR, Uruguay, and Ricardo Bessa of INESC 1638 TEC, Portugal, who demonstrated collaborative ${ }^{1639}$ spirit but were not able to obtain the data relevant ${ }^{1640}$ 1641 for the study. David Trebosc and the bdpv plat- ${ }_{1642}$ form team are thanked for their engagement, high 1643 value work and their exemplary policy of openness, ${ }^{1644}$ which highly contributed to present work. Daniel ${ }^{1645}$ Decker from the Federal Network Agency in Ger- ${ }^{1646}$ many is thanked for the provision of the dataset 1648 and his kind support. We would like to thank ${ }^{1649}$ Mr Ruppel and Mr Ausburg (SMA) for their ef- ${ }^{1650}$ forts in gathering plant information while preserv- ${ }_{1652}$ ing the anonymity of the plants of the sunny por- 1653 tal. Lastly, we are mostly appreciative to those ${ }^{1654}$ websites that allowed us to freely download their ${ }^{1655}$ data: openpv.nrel.gov, pvoutput.org, solar-log.com, ${ }_{1657}$ sonnenertrag.eu, suntrol-portal.com. Another site ${ }^{1658}$ not used within the study that is an excellent source ${ }^{1659}$ is https://www.californiadgstats.ca.gov/, however, ${ }^{1660}$ the USA data collected from openpv.nrel.gov was ${ }_{1662}$ feared to already incorporate this data and so po- ${ }^{1663}$ tential duplication was avoided.

\section{References}

Bright, J.M., Babacan, O., Kleissl, J., Taylor, P.G., Crook, R., 2017a. A synthetic, spatially decorrelating solar irradiance generator and application to a LV grid model with high PV penetration. Solar Energy 147, 83-98. doi:10.1016/j.solener.2017.03.018.

Bright, J.M., Killinger, S., Lingfors, D., Engerer, N.A., 2017b. Improved satellite-derived PV power nowcasting using power data from real-time reference PV systems. Solar Energy doi:10.1016/j.solener.2017.10.091.

Bright, J.M., Killinger, S., van Sark, W., SaintDrenan, Y.M., Moriatis, P., Taylor, J., Engerer, N.A., 2018. ResearchGate project: Characteristics and statistics of PV system metadata. URL: https://www.researchgate.net/project/ Characteristics-and-statistics-of-PV-system-metadata.

Bright, J.M., Smith, C.J., Taylor, P.G., Crook, R., 2015. Stochastic generation of synthetic minutely irradiance time series derived from mean hourly weather observation data. Solar Energy 115, 229-242. doi:10.1016/j. solener.2015.02.032.

Elsinga, B., van Sark, W., 2015. Spatial power fluctuation correlations in urban rooftop photovoltaic systems. Progress in Photovoltaics: Research and Applications 23, 1390-1397. doi:10.1002/pip. 2539.

Elsinga, B., van Sark, W., Ramaekers, L., 2017. Inverse photovoltaic yield model for global horizontal irradiance reconstruction. Energy Science \& Engineering 5, 1-14. doi:10.1002/ese3.162

Freitas, S., Catita, C., Redweik, P., Brito, M.C., 2015. Modelling solar potential in the urban environment: State-ofthe-art review. Renewable and Sustainable Energy Reviews 41, 915-931. doi:10.1016/j.rser.2014.08.060.

IEA, 2018. 2018: Snapshot of global photovoltaic markets: Report IEA PVPS T1-33:2018. URL: http://www.iea-pvps.org/fileadmin/dam/public/ report/statistics/IEA_PVPS-A_Snapshot_of_Global_ PV-1992-2017.pdf.

IEA-PVPS, 2018. Performance and reliability of photovoltaic systems. URL: http://www.iea-pvps.org/index. php?id=57.

Ineichen, P., Perez, R., 2002. A new airmass independent 
formulation for the Linke turbidity coefficient. Solar En- 1711 ergy 73, 151-157. doi:10.1016/S0038-092X (02)00045-2. 1712

Jamaly, M., Bosch, J., Kleissl, J., 2013. A power con- 1713 version model for distributed PV systems in California 1714 using SolarAnywhere irradiation. URL: http:// 1715 calsolarresearch.ca.gov/images/stories/documents/ 1716 Sol1_funded_proj_docs/UCSD/perf_model_v11.pdf. 1717 Killinger, S., Braam, F., Müller, B., Wille-Haussmann, B., 1718 McKenna, R., 2016. Projection of power generation be- 1719 tween differently-oriented PV systems. Solar Energy 136, 1720 153-165. doi:10.1016/j.solener.2016.06.075. 1721

Killinger, S., Bright, J.M., Lingfors, D., Engerer, N.A., 1722 2017a. A tuning routine to correct systematic influences 1723 in reference PV systems' power outputs. Solar Energy 1724 157, 1082-1094. doi:10.1016/j.solener.2017.09.001. 1725 Killinger, S., Engerer, N., Müller, B., 2017b. QCPV: A qual- 1726 ity control algorithm for distributed photovoltaic array 1727 power output. Solar Energy 143, 120-131. doi:10.1016/ 1728 j.solener.2016.12.053.

Killinger, S., Guthke, P., Semmig, A., Müller, B., Wille- 1730 Haussmann, B., Fichtner, W., 2017c. Upscaling PV 1731 Power Considering Module Orientations. IEEE Journal 1732 of Photovoltaics 7, 941-944. doi:10.1109/JPHOTOV.2017. 1733 2684908.

Kühnert, J., 2016. Development of a photovoltaic power pre- 1735 diction system for forecast horizons of several hours. PhD 1736 Thesis. Universität Oldenburg. Oldenburg, Germany. 1737 Leloux, J., Narvarte, L., Trebosc, D., 2012a. Review of 1738 the performance of residential PV systems in Belgium. 1739 Renewable and Sustainable Energy Reviews 16, 178-184. 1740 doi:10.1016/j.rser.2011.07.145.

Leloux, J., Narvarte, L., Trebosc, D., 2012b. Review of the 1742 performance of residential PV systems in France. Re- 1743 newable and Sustainable Energy Reviews 16, 1369-1376. 1744 doi:10.1016/j.rser.2011.10.018.

1745

Lingfors, D., Bright, J.M., Engerer, N.A., Ahlberg, J., 1746 Killinger, S., Widén, J., 2017. Comparing the capabil- 1747 ity of low- and high-resolution LiDAR data with applica- 1748 tion to solar resource assessment, roof type classification 1749 and shading analysis. Applied Energy 205, 1216-1230. 1750 doi:10.1016/j.apenergy . 2017.08.045.

Lingfors, D., Killinger, S., Engerer, N.A., Widén, J., Bright, 1752 J.M., 2018. Identification of PV system shading using a 1753
LiDAR-based solar resource assessment model: an evaluation and cross-validation. Solar Energy 159, 157-172. doi:10.1016/j.solener.2017.10.061.

Lingfors, D., Widén, J., 2016. Development and validation of a wide-area model of hourly aggregate solar power generation. Energy 102, 559-566. doi:10.1016/j . energy . 2016. 02.085 .

Lorenz, E., Scheidsteger, T., Hurka, J., Heinemann, D., Kurz, C., 2011. Regional PV power prediction for improved grid integration. Progress in Photovoltaics: Research and Applications 19, 757-771. doi:10.1002/pip. 1033.

Mainzer, K., Killinger, S., McKenna, R., Fichtner, W., 2017. Assessment of rooftop photovoltaic potentials at the urban level using publicly available geodata and image recognition techniques. Solar Energy 155, 561-573. doi:10.1016/j.solener.2017.06.065.

Matlab, 2018. MathWorks: Documentation: Fitdist: Distribution Names. URL: https://mathworks.com/help/ stats/fitdist.html\#btu538h-distname.

McNeil, I., 1990. An Encyclopaedia of the history of technolology. Routledge reference, Routledge, London, England.

Moraitis, P., Kausika, B., van Sark, Wilfried G. J. H. M., 2015. Visualization of operational performance of gridconnected PV systems in selected European countries, in: 42nd IEEE Photovoltaic Specialists Conference (PVSC), New Orleans, USA. doi:10.1109/PVSC.2015.7355613.

National Grid UK, 2018. Demand data 2018. URL: https://www.nationalgrid.com/uk/electricity/ market-operations-and-data/data-explorer.

Nordmann, T., Clavadetscher, L., van Sark, Wilfried G. J. H. M., Green, M., 2014. Analysis of Long-Term Performance of PV Systems: Different Data Resolution for Different Purposes. Report IEA-PVPS T13-05:2014.

ofgem, 2018. Feed-In Tariff (FIT) rates. URL: https: //www. of gem.gov.uk/environmental-programmes/fit/ fit-tariff-rates.

Pareek, S., Chaturvedi, N., Dahiya, R., 2017. Optimal interconnections to address partial shading losses in solar photovoltaic arrays. Solar Energy 155, 537-551. doi:10.1016/j.solener.2017.06.060.

Paulescu, M., Paulescu, E., Gravila, P., Badescu, V., 2012. 
Weather modeling and forecasting of PV systems opera- 1797 tion. Green Energy and Technology, Springer, Dordrecht, 1798 Germany.

Pfenninger, S., Staffell, I., 2016. Long-term patterns of 1800 European PV output using 30 years of validated hourly 1801 reanalysis and satellite data. Energy 114, 1251-1265. 1802 doi:10.1016/j .energy . 2016.08.060.

Reich, N.H., Mueller, B., Armbruster, A., van Sark, Wil- 1804 fried G. J. H. M., Kiefer, K., Reise, C., 2012. Perfor- 1805 mance ratio revisited: is $\mathrm{PR}>90 \%$ realistic? Progress 1806 in Photovoltaics: Research and Applications 20, 717-726. 1807 doi:10.1002/pip. 1219.

Saint-Drenan, Y.M., 2015. A probabilistic approach to 1809 the estimation of regional photovoltaic power generation 1810 using meteorological data: Application of the Approach 1811 to the German Case. Ph.D. thesis. University of Kassel. 1812 Kassel, Germany. URL: https://kobra.bibliothek. 1813 uni-kassel.de/bitstream/urn:nbn:de:hebis: 1814 34-2016090550868/3/DissertationYMSaintDrenan.pdf. 1815 Saint-Drenan, Y.M., Fritz, R., Jost, D., 2015. Auswertung 1816 des Effekts der Sonnenfinsternis vom 20.03.2015 auf das 1817 deutsche Energieversorgungssystem. URL: http://www. 1818 energiesystemtechnik.iwes.fraunhofer.de.

Saint-Drenan, Y.M., Good, G.H., Braun, M., 2017. A prob- 1820 abilistic approach to the estimation of regional photo- 1821 voltaic power production. Solar Energy 147, 257-276. 1822 doi:10.1016/j.solener.2017.03.007.

Saint-Drenan, Y.M., Good, G.H., Braun, M., Freisinger, T., 1824 2016. Analysis of the uncertainty in the estimates of re- 1825 gional PV power generation evaluated with the upscal- 1826 ing method. Solar Energy 135, 536-550. doi:10.1016/j · 1827 solener.2016.05.052.

Saint-Drenan, Y.M., Wald, L., Ranchin, T., Dubus, L., 1829 Troccoli, A., 2018. An approach for the estimation 1830 of the aggregated photovoltaic power generated in sev- 1831 eral European countries from meteorological data. Ad- 1832 vances in Science and Research 15, 51-62. doi:10.5194/ asr-15-51-2018.

Schläpfer, M., Lee, J., Bettencourt, L.M.A., 2015. Ur- ${ }_{1833}$ ban Skylines: building heights and shapes as measures of city size. URL: http://arxiv.org/abs/1512.00946, ${ }^{1834}$ arXiv: 1512.00946.

Schubert, G., 2012. Modellierung der stündlichen ${ }^{1835}$
Photovoltaik- und Windstromeinspeisung in Europa, in: 12. Symposium Energieinnovation, Graz, Austria.

SMHI, 2015. STRÅNG - a mesoscale model for solar radiation. URL: http://strang.smhi.se/.

Š́ri, M., Huld, T.A., Dunlop, E.D., Ossenbrink, Heinz A., 2007. Potential of solar electricity generation in the European Union member states and candidate countries. Solar Energy 81, 1295-1305. doi:10.1016/j.solener.2006.12. 007.

Swedish Land Survey, 2015. Produktbeskrivning: Laserdata [Product description LiDAR data] ver. 2.2. Technical Report 12. Swedish Land Survey. Gävle. URL: http://www.lantmateriet.se/globalassets/ kartor-och-geografisk-information/hojddata/ produktbeskrivningar/laserdat.pdf.

Swedish Land Survey, 2016. Produktbeskrivning GSDFastighetskartan, vektor [Product description Property Map, vectorized]. Technical Report. Swedish Land Survey. Gävle. URL: https://www.lantmateriet.se/ globalassets/kartor-och-geografisk-information/ kartor/produktbeskrivningar/fastshmi.pdf.

Taylor, J., 2015. Performance of distributed PV in the UK: a statistical analysis of over 7000 systems, in: 31st European Photovoltaic Solar Energy Conference and Exhibition, Hamburg, Germany.

Tsafarakis, O., Moraitis, P., Kausika, B.B., van der Velde, H., 't Hart, S., de Vries, A., de Rijk, P., de Jong, M.M., van Leeuwen, H.P., van Sark, W., 2017. Three years experience in a Dutch public awareness campaign on photovoltaic system performance. IET Renewable Power Generation 11, 1229-1233. doi:10.1049/iet-rpg.2016.1037. Yang, D., Dong, Z., Reindl, T., Jirutitijaroen, P., Walsh, W.M., 2014. Solar irradiance forecasting using spatiotemporal empirical kriging and vector autoregressive models with parameter shrinkage. Solar Energy 103, 550-562. doi:10.1016/j.solener.2014.01.024.

\section{Appendix A. Approximation of parameters in clusters: continued}

The appendix is a continuation of section 4 and provides histograms together with fitted distribu- 
${ }_{1837}$ tions of azimuth, tilt, specific annual yield and in-

${ }_{1838}$ stalled capacity for system sizes $>25 \mathrm{kWp}$ in Fig-

1839 ure A.10. Table A.4 presents the coefficients of the

1840 fitted distributions, while distinguishing between

${ }_{1841}$ systems $\leq 25 \mathrm{kWp}$ and $>25 \mathrm{kWp}$. All distri-

${ }_{1842}$ bution functions are defined in Table A.3 and can

${ }_{1843}$ be replicated with help of the parametrised coeffi-

1844 cients. It is important that the user reads carefully

1845 section 4 in order to appropriately use the distribu-

1846 tions. A summary of the impact of our proposed

${ }_{1847}$ quality control criteria from section 2 is provided

${ }_{1848}$ in the appendix in Table A.5 where percentages of

1849 removed data are presented. 

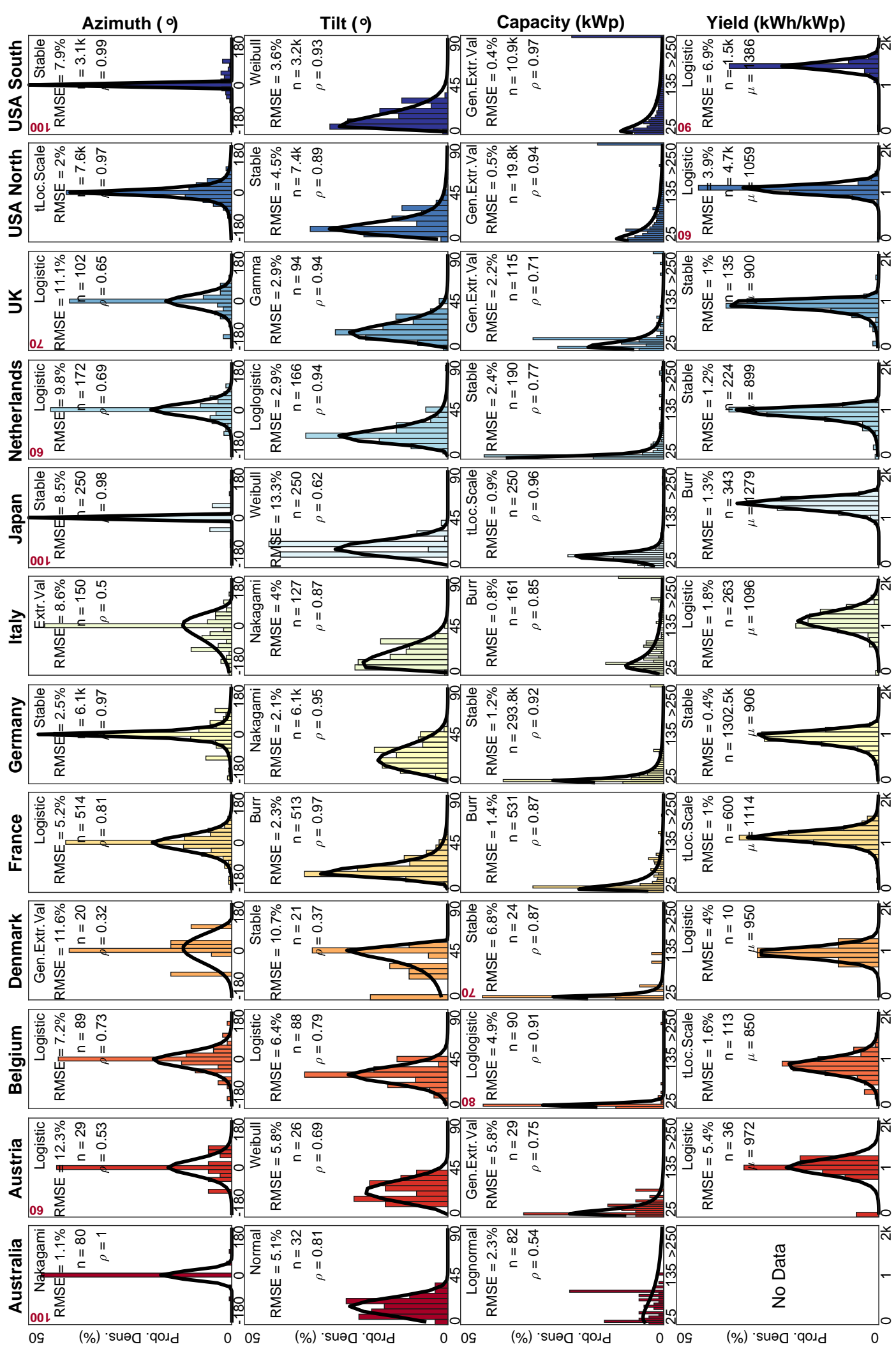
Table A.3: Definition of the probability density distributions used in the research. The coefficients correspond to those presented in Table A.4. The distribution name corresponds to the same Matlab®distribution names and readers are encourage to read the detailed descriptions at WwW.MATHWORKS.COM/HELP/STATS/CONTINUOUS-DISTRIBUTIONS.htML. Each coefficient is defined. The equation is provided from the Matlabßdocumentation. Note that the Stable distribution is not explicitly a probability density function, but a characteristic function.

\begin{tabular}{|c|c|c|c|c|c|}
\hline $\begin{array}{l}\text { Distribution } \\
\text { Name }\end{array}$ & Coeff. 1 & Coeff. 2 & Coeff. 3 & Coeff. 4 & Probability Density Function, $f(x \mid \ldots)$ \\
\hline Burr type XII & $\begin{array}{l}\alpha \\
\text { Scale }\end{array}$ & $\begin{array}{l}c \\
\text { Shape } 1 \\
\end{array}$ & $\begin{array}{l}k \\
\text { Shape } 2 \\
\end{array}$ & - & $f(x \mid \alpha, c, k)=\frac{\frac{k c}{\alpha}\left(\frac{x}{\alpha}\right)^{c-1}}{\left(1+\left(\frac{x}{\alpha}\right)^{c}\right)^{k+1}}$ \\
\hline Extreme Value & $\begin{array}{l}\mu \\
\text { Location }\end{array}$ & $\begin{array}{l}\sigma \\
\text { Scale }\end{array}$ & - & - & $f(x \mid \mu, \sigma)=-\sigma^{-1} \exp \left(\frac{x-\mu}{\sigma}\right) \exp \left(-\exp \left(\frac{x-\mu}{\sigma}\right)\right)$ \\
\hline Gamma & $\begin{array}{l}a \\
\text { Shape }\end{array}$ & $\begin{array}{l}b \\
\text { Scale }\end{array}$ & - & - & $f(x \mid a, b)=\frac{1}{b^{a} \Gamma(a)} x^{a-1} \exp \left(\frac{-x}{b}\right)$ \\
\hline $\begin{array}{l}\text { Generalized } \\
\text { Extreme Value }\end{array}$ & $\begin{array}{l}k \\
\text { Shape }\end{array}$ & $\begin{array}{l}\sigma \\
\text { Scale }\end{array}$ & $\begin{array}{l}\mu \\
\text { Location }\end{array}$ & - & $\begin{array}{l}f(x \mid k, \mu, \sigma)= \\
\left(\frac{1}{\sigma}\right) \exp \left(-\left(1+k \frac{(x-\mu)}{\sigma}\right)^{-\frac{1}{k}}\right)\left(1+k \frac{(x-\mu)}{\sigma}\right)^{-1-\frac{1}{k}}\end{array}$ \\
\hline $\begin{array}{l}\text { Inverse } \\
\text { Gaussian }\end{array}$ & $\begin{array}{l}\mu \\
\text { Scale }\end{array}$ & $\begin{array}{l}\lambda \\
\text { Shape }\end{array}$ & - & - & $f(x \mid \mu, \lambda)=\sqrt{\frac{\lambda}{2 \pi x^{3}}} \exp \left(-\frac{\lambda}{2 \mu^{2} x}(x-\mu)^{2}\right)$ \\
\hline Logistic & $\begin{array}{l}\mu \\
\text { Location }\end{array}$ & $\begin{array}{l}\sigma \\
\text { Scale }\end{array}$ & - & - & $f(x \mid \mu, \sigma)=\frac{\exp \left(\frac{x-\mu}{\sigma}\right)}{\sigma\left(1+\exp \left(\frac{x-\mu}{\sigma}\right)^{2}\right.}$ \\
\hline Loglogistic & $\begin{array}{l}\mu \\
\text { Log Loc. }\end{array}$ & $\begin{array}{l}\sigma \\
\text { Log Scale } \\
\end{array}$ & - & - & $f(x \mid \mu, \sigma)=\frac{1}{\sigma} \frac{1}{x} \frac{\exp \left(\frac{\log (x)-\mu}{\sigma}\right)}{\left(1+\exp \left(\frac{\log (x)-\mu}{\sigma}\right)\right)^{2}} \frac{1}{\Gamma(\mu)} x^{2 \mu-1}$ \\
\hline Lognormal & $\begin{array}{l}\mu \\
\text { Log Loc. }\end{array}$ & $\begin{array}{l}\sigma \\
\text { Log. } \\
\text { Scale }\end{array}$ & - & - & $f(x \mid \mu, \sigma)=\frac{1}{x \sigma \sqrt{2 \pi}} \exp \left(\frac{-(\ln x-\mu)^{2}}{2 \sigma^{2}}\right)$ \\
\hline Nakagami & $\begin{array}{l}\mu \\
\text { Shape }\end{array}$ & $\begin{array}{l}\omega \\
\text { Scale }\end{array}$ & - & - & $f(x \mid \mu, \omega)=2\left(\frac{\mu}{\omega}\right)^{\mu} \frac{1}{\Gamma(\mu)} x^{(2 \mu-1)} \exp \left(\frac{-\mu x^{2}}{\omega}\right)$ \\
\hline Normal & $\begin{array}{l}\mu \\
\text { Location }\end{array}$ & $\begin{array}{l}\sigma \\
\text { Scale }\end{array}$ & - & - & $f(x \mid \mu, \sigma)=\frac{1}{\sigma \sqrt{2 \pi}} \exp \left(\frac{-(x-\mu)^{2}}{2 \sigma^{2}}\right)$ \\
\hline Stable & $\begin{array}{l}\alpha \\
\text { Shape } 1\end{array}$ & $\begin{array}{l}\beta \\
\text { Shape } 2\end{array}$ & $\begin{array}{l}\gamma \\
\text { Scale }\end{array}$ & $\begin{array}{l}\delta \\
\text { Location }\end{array}$ & $\begin{array}{l}E\left(e^{i t X}\right)= \\
\exp \left(-\gamma^{\alpha}|t|^{\alpha}\left(1+i \beta \operatorname{sgn}(t) \tan \frac{\pi \alpha}{2}\left((\gamma|t|)^{1-\alpha}-1\right) i \delta t\right)\right.\end{array}$ \\
\hline t Location-Scale & $\begin{array}{l}\mu \\
\text { Location }\end{array}$ & $\begin{array}{l}\sigma \\
\text { Scale }\end{array}$ & $\begin{array}{l}\nu \\
\text { Deg. of } \\
\text { Freedom }\end{array}$ & - & $f(x \mid \mu, \sigma, \nu)=\frac{\Gamma\left(\frac{\nu+1}{2}\right)}{\sigma \sqrt{\nu \pi} \Gamma\left(\frac{\nu}{2}\right)}\left(\frac{\nu+\left(\frac{x-\mu}{\sigma}\right)^{2}}{\nu}\right)^{-\left(\frac{\nu+1}{2}\right)}$ \\
\hline Weibull & $\begin{array}{l}a \\
\text { Scale }\end{array}$ & $\begin{array}{l}b \\
\text { Shape }\end{array}$ & - & - & $f(x \mid a, b)=\frac{b}{a}\left(\frac{x}{a}\right)^{b-1} \exp \left(-\left(\frac{x}{a}\right)^{b}\right)$ \\
\hline
\end{tabular}




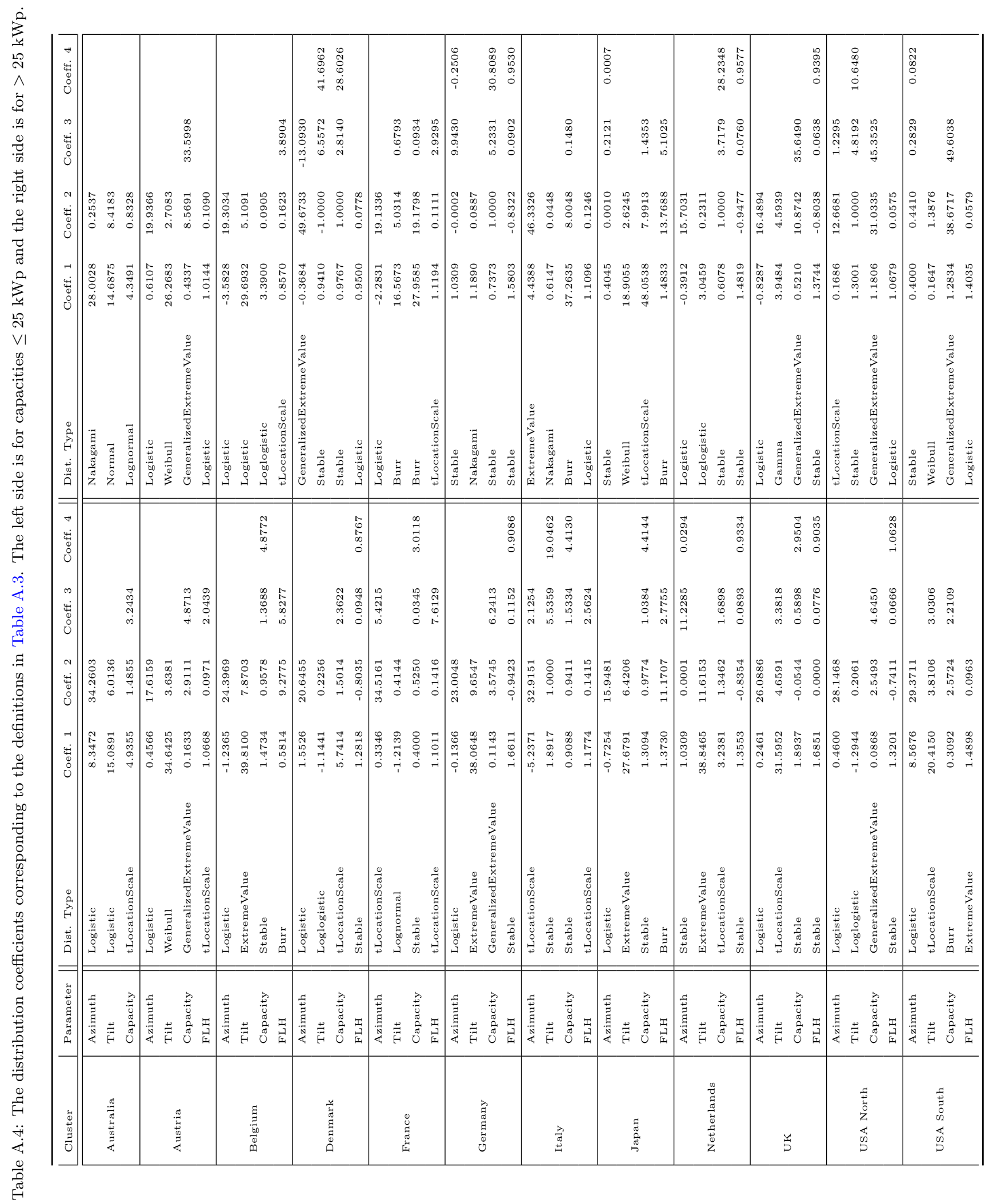




\begin{tabular}{|c|c|c|c|c|c|c|c|c|c|c|c|c|}
\hline 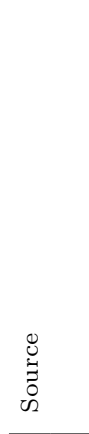 & 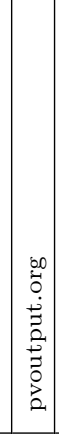 & 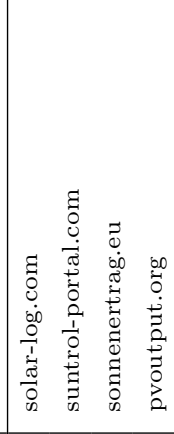 & 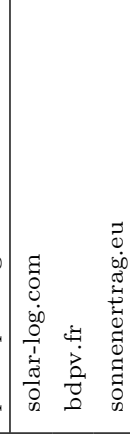 & 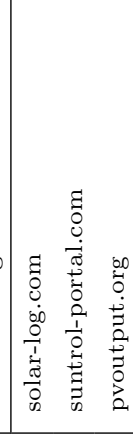 & 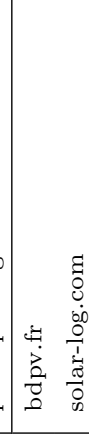 & 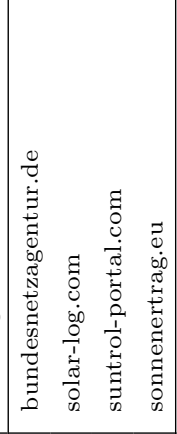 & 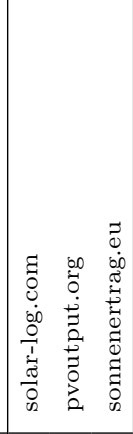 & 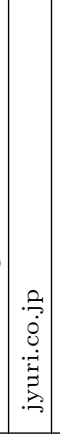 & 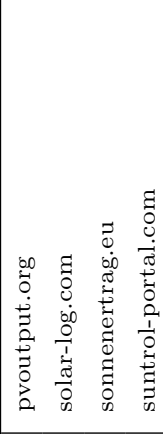 & 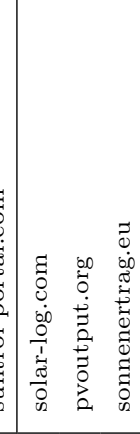 & 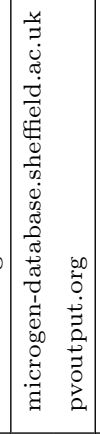 & 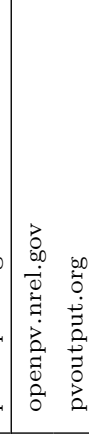 \\
\hline $\begin{array}{l}8 \\
\stackrel{0}{N} \\
\wedge\end{array}$ & $\stackrel{8}{0}$ & $\begin{array}{llll}8 & 8 & 8 & 0 \\
0 & 0 & 0 & 0 \\
0 & 0 & 0\end{array}$ & 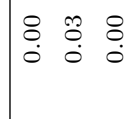 & $\begin{array}{lll}8 & 8 & 8 \\
0 & 0 & 0\end{array}$ & $\begin{array}{ll}0 & 8 \\
0 & 8 \\
0 & 0\end{array}$ & $\mid \begin{array}{llll}5 & 8 & 8 & 8 \\
0 & 0 & 0 & 0 \\
0 & 0 & 0\end{array}$ & $\begin{array}{lll}8 & 0 & 8 \\
0 & 0 & 0 \\
0\end{array}$ & $\begin{array}{l}8 \\
0 \\
0\end{array}$ & $\left(\begin{array}{llll}8 & 8 & 8 & 8 \\
0 & 0 & 0 & 0 \\
0 & 0 & 0\end{array}\right.$ & $\mid \begin{array}{lll}0 & 1 & 0 \\
0 & 0 & 0 \\
0 & 0 & 0\end{array}$ & $\mid$\begin{tabular}{ll}
$\infty$ & 0 \\
\hdashline & 0 \\
0 & 0
\end{tabular} & 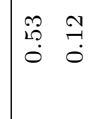 \\
\hline 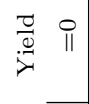 & $\begin{array}{l}8 \\
0 \\
0\end{array}$ & 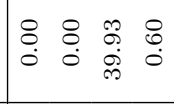 & $\begin{array}{ll}0 \\
0 \\
0\end{array}$ & 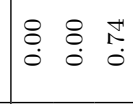 & \begin{tabular}{ll}
$\Re$ & 8 \\
\hdashline & 8 \\
0 & 0
\end{tabular} & $\mid$\begin{tabular}{cccc}
0 & 0 & 0 & 0 \\
\hdashline & 0 & 0 & 0 \\
0 & 0 & 0 & 0 \\
0
\end{tabular} & 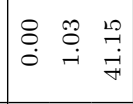 & $\stackrel{8}{\circ}$ & 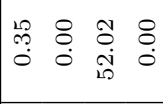 & $\mid \begin{array}{ccc}0 & 0 & 8 \\
0 & 0 & 0 \\
0 & \infty & 0 \\
0\end{array}$ & 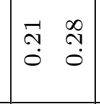 & 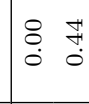 \\
\hline ֻُ & $\begin{array}{l}8 \\
0 \\
0\end{array}$ & 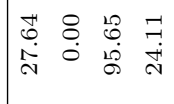 & 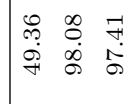 & 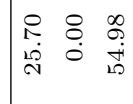 & 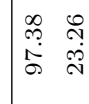 & $\left|\begin{array}{llll}R & \overrightarrow{0} & 0 & 0 \\
0 & 0 \\
0 & 0 & 0 \\
0 & 0 & 0 & 0 \\
0\end{array}\right|$ & 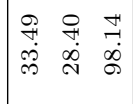 & 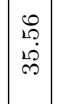 & 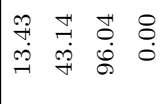 & 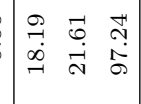 & 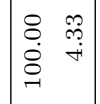 & 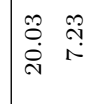 \\
\hline 窇 & 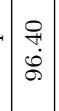 & $\begin{array}{llll}8 & 8 & 0 & 0 \\
0 & \dot{0} & 0 & 0 \\
0 & 0 & 0 & 0 \\
-1 & 0 & 0\end{array}$ & 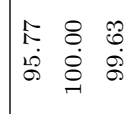 & 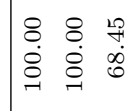 & 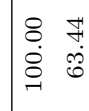 & 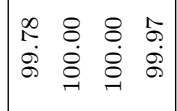 & 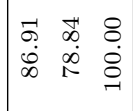 & \begin{tabular}{c}
8 \\
$\stackrel{+}{0}$ \\
$\vdots$ \\
\hdashline
\end{tabular} & $\begin{array}{llll}8 & 8 & 8 & 8 \\
1 & \dot{1} & \dot{1} & \dot{0} \\
1 & 0 & - & 0\end{array}$ & 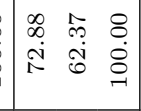 & 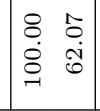 & 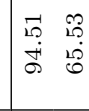 \\
\hline 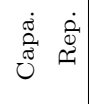 & $\mid$\begin{tabular}{l}
0 \\
0 \\
$\dot{0}$ \\
\hdashline
\end{tabular} & 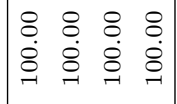 & $\mid \begin{array}{lll}0 & 0 & 0 \\
\dot{0} & \dot{0} & 0 \\
0 & 0 & 0 \\
-1 & 0\end{array}$ & 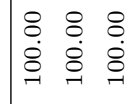 & $\mid$\begin{tabular}{ll}
0 & 0 \\
$\dot{0}$ & $\dot{0}$ \\
0 & 0 \\
\hdashline & 0
\end{tabular} & 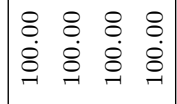 & \begin{tabular}{lll}
8 & 0 & 0 \\
$\dot{0}$ & $\dot{0}$ & $\dot{0}$ \\
\hdashline & 0 & 0 \\
-1
\end{tabular} & \begin{tabular}{c}
8 \\
$\stackrel{+}{0}$ \\
$\vdots$ \\
\hdashline
\end{tabular} & 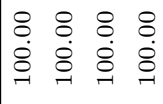 & $\mid$\begin{tabular}{lll}
0 & 0 & 0 \\
0 & 0 & 0 \\
0 & 0 & 0 \\
\hdashline & 0 \\
\hdashline & 0
\end{tabular} & 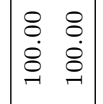 & $\mid \begin{array}{ll}0 & 0 \\
\dot{0} & \dot{0} \\
0 & 0\end{array}$ \\
\hline $\begin{array}{l}0 \\
\text { Oे } \\
1 \\
1 \\
\wedge\end{array}$ & $\stackrel{8}{0}$ & $\left|\begin{array}{llll}8 & \overrightarrow{1} & 8 & 8 \\
0 & 0 & 0 & 0 \\
0 & 0 & 0\end{array}\right|$ & $\begin{array}{lll}8 & 8 & 8 \\
0 & 0 & 0\end{array}$ & 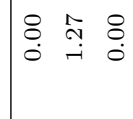 & $\begin{array}{ll}1 & 8 \\
-7 & 0 \\
0 & 0\end{array}$ & $\mid \begin{array}{cccc}8 & 0 & \overrightarrow{0} & 0 \\
0 & 0 & 0 \\
0 & 0 & -i & 0\end{array}$ & $\begin{array}{lll}8 & 0 & 0 \\
0 & 0 & 0 \\
0 & 0 & 0\end{array}$ & $\begin{array}{l}8 \\
\vdots \\
0\end{array}$ & 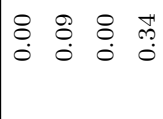 & $\mid \begin{array}{lll}0 & 0 & 0 \\
0 & 0 & 0 \\
0 & 0 & 0\end{array}$ & $\mid \begin{array}{ll}0 \\
\vdots \\
0 & 0 \\
0\end{array}$ & $\left(\begin{array}{ll}0 \\
0 \\
0 & 8 \\
0\end{array}\right.$ \\
\hline 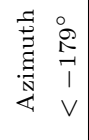 & 官 & 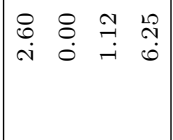 & 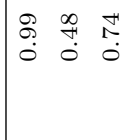 & 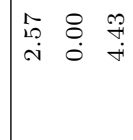 & $\begin{array}{ll}\vec{b} & \delta \\
0 & 10\end{array}$ & 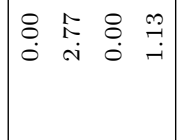 & 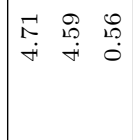 & 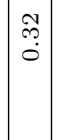 & 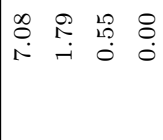 & 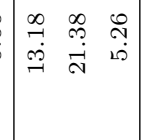 & $\mid \begin{array}{cc}\infty & + \\
0 & 0 \\
0 & + \\
\end{array}$ & 总 \\
\hline ֻّ & 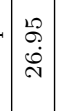 & 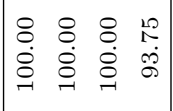 & $\begin{array}{lll}8 & 0 & 0 \\
0 & \dot{0} \\
0 & 0 & 0 \\
-1 & 0 \\
-1\end{array}$ & 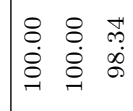 & 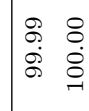 & $\begin{array}{cccc}0 & 0 & 0 & 0 \\
0 & 0 & 0 & 0 \\
0 & 0 & 0 & 0 \\
-1 & 0 & 0\end{array} \mid$ & $\begin{array}{lll}8 & 0 & 0 \\
0 & 0 \\
0 & 0 & 0 \\
0 & 0 & 0 \\
-1\end{array}$ & \begin{tabular}{c}
8 \\
$\stackrel{+}{0}$ \\
$\vdots$ \\
\hdashline
\end{tabular} & 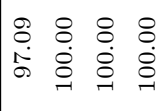 & $\mid \begin{array}{lll}0 & 0 & 0 \\
0 & 0 & 0 \\
0 & 0 & 0 \\
-1 & 0 & 0\end{array}$ & $\mid \begin{array}{cc}8 & 0 \\
0 & 0 \\
0 & 0 \\
0 & 0\end{array}$ & 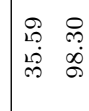 \\
\hline $\begin{array}{l}\stackrel{0}{\infty} \\
\wedge \\
\wedge\end{array}$ & $\begin{array}{l}8 \\
\dot{0}\end{array}$ & 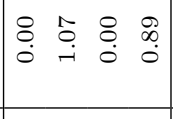 & $\begin{array}{lll} & 0 & 0 \\
0 & 0 & 0 \\
0 & 0 & 0\end{array}$ & $\begin{array}{lll}7 & 0 & 8 \\
0 & 0 & 0 \\
0 & 0\end{array}$ & $\left(\begin{array}{ll}0 & 0 \\
0 & 0 \\
0 & 0\end{array}\right.$ & 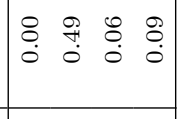 & 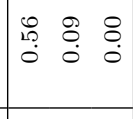 & $\stackrel{8}{0}$ & 号 & $\left|\begin{array}{lll}0 & 0 & 0 \\
& 0 & 0 \\
-1 & 0 & 0\end{array}\right|$ & \begin{tabular}{ll}
8 \\
\hdashline \\
0 & 0 \\
0 & 0
\end{tabular} & $\begin{array}{ll}5 & 8 \\
0 & 0\end{array}$ \\
\hline 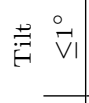 & 10 & 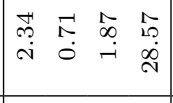 & 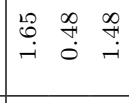 & 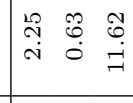 & 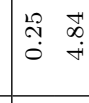 & 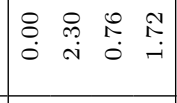 & 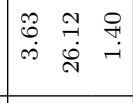 & $\begin{array}{l}8 \\
0 \\
0\end{array}$ & 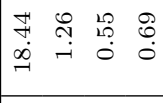 & 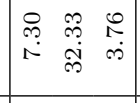 & 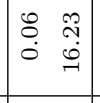 & $\begin{array}{ll}20 \\
0 \\
0 & : \\
0 & \stackrel{\leftrightarrow}{0}\end{array}$ \\
\hline$\dot{\stackrel{q}{q}}$ & $\begin{array}{l}2 \\
g \\
\dot{\rho} \\
i\end{array}$ & 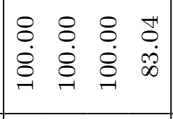 & 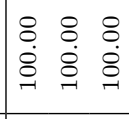 & 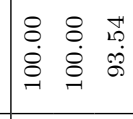 & $\begin{array}{ll}8 & 8 \\
\dot{0} & \stackrel{8}{0} \\
\dot{0} & \stackrel{0}{-1}\end{array}$ & 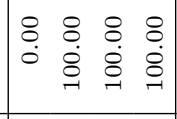 & 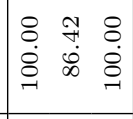 & $\begin{array}{l}8 \\
\stackrel{1}{+} \\
\stackrel{8}{-1}\end{array}$ & 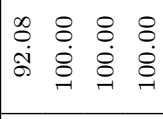 & $\mid \begin{array}{ccc}0 & 0 & 0 \\
0 & 0 \\
0 & \infty & 0 \\
0 & \infty & 0 \\
-1 & & -1 \\
\end{array}$ & 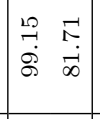 & 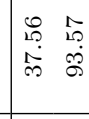 \\
\hline 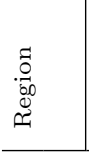 & 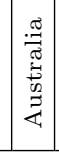 & 要 & 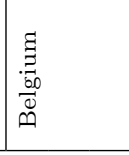 & 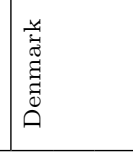 & 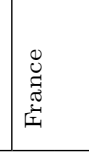 & & 苞 & $\mid$ & 离 & 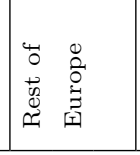 & 5 & 政 \\
\hline
\end{tabular}

